\title{
Efeitos Regionais da Política Monetária: o Caso do Estado do Espírito Santo*
}

\section{Regional Effects of the Monetary Policy: the Case of the State of Espirito Santo}

\author{
Sávio Bertochi Caçador** \\ Edson Zambon Monte*** \\ Ricardo Ramalhete Moreira*** *
}

\begin{abstract}
Resumo: Este artigo se propõe a estimar os impactos da política monetária na economia do estado do Espírito Santo, no período 2000-2010, usando a técnica de vetores autorregressivos (VAR). A base de dados utilizada é mensal e as variáveis analisadas são, a grosso modo, de cunho monetário, cambial, de atividade econômica, de preços e de arrecadação tributária, tanto para o Espírito Santo quanto para o Brasil. A contribuição do artigo reside na análise específica de uma economia com características peculiares, como a participação substancial de empresas de pequeno porte, a baixa participação no crédito nacional e o elevado grau de abertura externa, o que resultou num impacto maior em alguns indicadores estudados para a economia local do que para a economia nacional.
\end{abstract}

Palavras-chave: Política monetária. Economia regional. Vetores autorregressivos. Economia do Espírito Santo.

Abstract: It is proposed to estimate the impacts of monetary policy in Espírito Santo's economy in the period 2000-2010 using vector auto-regression (VAR) technique. The database is monthly and the variables analyzed are, roughly, monetary, exchange rate, economic activity, prices and tax revenues, both for Espírito Santo and Brazil. The paper's contribution lies on the specific analysis of an economy with peculiar characteristics, such as substantial participation of small businesses, low participation in the national credit and high degree of external openness, which has resulted in a greater impact on the indicators studied for the local economy than to the national economy.

\footnotetext{
* Vale a ressalva de que as opiniões contidas nesse estudo não refletem a opinião do Banco de Desenvolvimento do Espírito Santo (Bandes) ou de algum outro membro dessa instituição.

** Mestre em Economia pela UFES. Economista do Bandes. E-mail: sbcacador@hotmail.com

*** Mestre em Economia pela UFES. Professor do Departamento de Economia da UFES. E-mail: edsonzambon@yahoo.com.br

*** * Doutor em Economia pelo IE/UFRJ. Professor do Programa de Pós-Graduação em Economia da Universidade Federal do Espírito Santo (UFES). E-mail: ramalhete.s@gmail.com
} 
Keywords: Monetary policy. Regional economics. Vector auto-regression. Espírito Santo's economy.

JEL Classification: E52; R11; C32.

\section{1 lntrodução}

Sempre que surgem pressões inflacionárias na economia brasileira e o Banco Central do Brasil (BCB) julga necessário colocar em prática políticas monetárias restritivas, alguns representantes de setores produtivos (sobretudo os ligados à indústria e ao comércio) reclamam diante das expectativas futuras negativas para a atividade econômica. Essa tem sido a tônica nas discussões sobre inflação e política monetária no país, desde a implementação do Sistema de Metas de Inflação $(\mathrm{SMI}){ }^{1}$

Obviamente, nem todas as atividades produtivas são impactadas da mesma maneira a partir de uma alteração das condições monetárias gerais, ou através de uma mudança na taxa básica Selic, em particular - ver, por exemplo, Tomazzia e Meurer (2009). Alguns setores são mais afetados, como os que dependem em maior medida das condições de crédito (por exemplo, os de bens de consumo duráveis, de bens de capital e da construção) ou os que são compostos por pequenas e médias empresas, as quais não têm acesso a mecanismos de obtenção de recursos alternativos ao crédito bancário, tais como abertura de capital e/ou lançamento de títulos de renda fixa (debêntures ou commercial papers). Por outro lado, as regiões, estados e, mesmo, as cidades que compõem os limites territoriais de um país são diferentemente afetadas, pois possuem diferentes composições de empresas e indústrias.

Em função disso, alguns trabalhos foram produzidos no Brasil para examinar empiricamente como a atividade econômica regional responde a ações de política monetária. Nessa linha, trabalhos como o de Fonseca e Vasconcelos (2003), Araújo (2004), Chumvichitra (2004), Rocha (2007), Bertanha e Haddad (2008) e Fonseca e Medeiros (2011) são algumas referências do tema no país. Desses, Fonseca e Vasconcelos (2003), usando dados de crédito, Bertanha e Haddad (2008), adotando o nível de emprego como uma proxy da atividade econômica, e Fonseca e Medeiros (2011), utilizando dados de produção industrial e oferta de crédito, incluíram o Espírito Santo em suas amostras.

Na literatura econômica local, Magalhães et al. (2009) abordaram de certa forma o assunto ao estudarem o efeito quantitativo de eventos que tendem a acentuar o grau de incerteza e da taxa de juros no nível de atividade. No entanto, a economia capixaba possui características peculiares, tais como elevado grau de

O SMI teve início em 21 de junho de 1999, por meio do Decreto nº 3.088 . 
abertura externo, forte co-movimento no nível de atividade com o país e alguns estados do Sudeste e do Sul, as quais a torna mais vulnerável aos efeitos da política monetária. Esse co-movimento que a economia capixaba possui com alguns estados do Sudeste e do Sul pode ser explicado pelo seu comércio inter-regional, importante para seu nível de atividade (MOTA, 2002).

Por isso, o objetivo deste trabalho é analisar os impactos da política monetária na economia capixaba no período 2000-2010, usando a técnica de vetores autorregressivos (VAR), a mais comum na literatura para esse tipo de estudo. A base de dados é mensal e as variáveis analisadas são, grosso modo, de cunho monetário, cambial, de atividade econômica, de preços e de arrecadação tributária, tanto para o Espírito Santo quanto para o Brasil. O trabalho apresenta detalhadamente as variáveis, suas unidades, siglas e fontes, na segunda seção.

O restante do artigo se divide sob a seguinte estrutura: na segunda seção, resgata-se parte da literatura teórica contemporânea sobre política monetária, em especial a literatura chamada de Nova Síntese Neoclássica, a qual vem balizando boa parte da pesquisa mundial acerca da prática das autoridades monetárias, e verifica-se também uma breve revisão da literatura internacional e nacional quanto aos efeitos regionais de política monetária; na terceira seção, sintetizam-se algumas características da economia do estado do Espírito Santo, objeto do presente trabalho; por sua vez, a quarta seção apresenta os procedimentos empíricos de análise, ou seja, a técnica VAR, e a base de dados utilizada na pesquisa; por fim, a quinta seção apresenta os principais resultados e evidências alcançadas para a economia capixaba, à luz dos resultados para a economia brasileira.

\section{Referencial Teórico}

\subsection{Política Monetária}

Parte fundamental da literatura internacional contemporânea acerca da dinâmica macroeconômica, e da política monetária em particular, é chamada de Nova Síntese Neoclássica, a qual possui uma "perspectiva híbrida". Híbrida porque os modelos da Nova Síntese podem ser considerados uma espécie de junção entre premissas novo-keynesianas e novo-clássicas (GOODFRIEND; KING, 1997). Pelo lado novo-keynesiano, considera-se a existência de concorrência monopolística e a rigidez de preços e/ou de salários. Essa é a dimensão do curto prazo, em que choques monetários possuem impacto real sobre a economia, via emprego, produção e renda.

Por outro lado, a dimensão do longo prazo é descrita por premissas novo-clássicas, aceitando-se flexibilidade perfeita de preços e otimização intertemporal. Nesse caso, os choques monetários possuem apenas impactos nominais, não 
havendo correlação entre política monetária e variáveis reais como produção e emprego.

Em geral, os modelos contemporâneos, sob a perspectiva da Nova Síntese, partem de três blocos. Num primeiro bloco, descreve-se a dinâmica da produção - uma curva IS dinâmica, autorregressiva e estocástica. As flutuações do PIB no entorno do produto potencial são explicadas a partir dos componentes de inércia produtiva (componente autorregressivo), de política monetária e de choques de demanda - com média zero e variância constante (BALL, 1999; SVENSSON, 1997).

Assim, desvios da produção face aos níveis normais ou potenciais são causados, em última instância, por choques de política fiscal, consumo, investimento e/ ou exportações líquidas (choques de demanda), ou, ainda, por desvios defasados da taxa básica de juros face à taxa neutra - isto é, a taxa de juros consistente com o produto potencial e com a estabilidade de preços (GALÍ; GERTLER, 2007). Alguns modelos com características forward-looking põem adicionalmente o produto como função da produção esperada e das taxas básicas de juros esperadas para os períodos futuros (CLARIDA; GALÍ; GERTLER, 1999).

Uma questão importante é que aquela taxa neutra - ou natural -, assim como os níveis potenciais de produção e emprego, é concebida como determinada unicamente pelo lado da oferta, ou seja, apenas por meio de fatores reais, tais como produtividade, propensão à poupança e preferências intertemporais de consumidores. Logo, a dinâmica estacionária da economia não possui correlação com a política monetária: vale, nesse caso, a hipótese de neutralidade da moeda no longo prazo.

Já num segundo bloco, descreve-se a taxa de inflação por meio de uma curva de Phillips dinâmica, autorregressiva e estocástica. A taxa de inflação é determinada por seus valores passados, pela dinâmica defasada do gap do produto - diferença entre produção efetiva e potencial em períodos passados - e ainda por um choque de oferta com média zero e variância constante. Logo, desvios do nível de preços em relação à meta inflacionária (implícita ou explícita em um sistema de inflation targeting) são determinados por um componente de inércia inflacionária - que tende a ser maior em contextos de baixa credibilidade do BCB -, pelos desvios da produção face ao nível potencial e por ocorrências eventuais e aleatórias em que há variações em preços fora do controle da política monetária, tais como os de energia em geral, alimentos e preços administrados e indexados. Considerando-se que, na média, tais choques são anulados, para os modelos da Nova Síntese a dinâmica dos desvios inflacionários é causada, em última instância, pelos desvios produtivos intertemporais.

Nessa perspectiva, portanto, a política monetária ótima é aquela que é consistente com uma trajetória de equilíbrio produtivo ou com gap do produto nulo 
ao longo do tempo, permitindo uma convergência intertemporal da taxa de inflação para a meta inflacionária.

Há ainda modelos em que a curva de Phillips apresenta componentes forward-looking e cambiais. Assim, a taxa de inflação e seus desvios são também causados por expectativas de inflação e de gap do produto, assim como por variações correntes e/ou esperadas na taxa de câmbio relevante (BLANCHARD; GALÍ, 2008; BOGDANSKI; TOMBINI; WERLANG, 2000).

Por sua vez, num terceiro bloco, coloca-se a solução do problema de política monetária, ou melhor, a regra de política monetária. Trata-se, em geral, de variantes da regra de Taylor (1993), em que as decisões de taxa básica de juros, por parte do $\mathrm{BCB}$, dependem da dinâmica observada e/ou esperada da atividade econômica e da inflação.

De fato, os modelos colocam a decisão de instrumento da autoridade monetária como função de toda a informação relevante no que diz respeito ao processo de determinação inflacionária. Logo, variáveis como câmbio e mark-up também podem entrar na regra de política monetária, a depender da estrutura das equações do modelo adotado.

Nessa perspectiva, o BCB deve ajustar a taxa real de juros de curto prazo com o intuito básico de promover a estabilidade inflacionária no longo prazo. Isso significa uma política contracíclica no curto prazo, ou seja, elevações da taxa real de juros quando são observados e/ou previstos desvios positivos de inflação e produto (isto é, inflação observada e/ou prevista maior que a meta de inflação e produto efetivo observado e/ou previsto maior que o produto potencial) e reduções da taxa real de juros quando desvios negativos de inflação e produto são verificados e/ou esperados.

Uma vez que a resposta do $\mathrm{BCB}$ aos choques inflacionários tem impactos defasados sobre a atividade econômica, deve-se avaliar a natureza de tais choques e adaptar a resposta da autoridade diante dessa avaliação, a fim de que sejam minimizadas as perdas sociais eventuais em decorrência da estratégia de controle inflacionário.

Em geral, a literatura recomenda uma resposta integral da política monetária face aos choques de demanda - visto que nesse caso a inflação resultaria de desvios produtivos e o seu contorno estaria sob o controle da autoridade - e propõe acomodações parciais dos choques de oferta, dado que aqui os desvios de inflação seriam causados por alterações de preços não correlacionadas com o ritmo da atividade econômica. Logo, a fim de que seja evitada uma perda desnecessária de produto ou crescimento do mesmo, o BCB deveria combater apenas parcialmente os choques de oferta (CLARIDA; GALÍ; GERTLER, 1999).

Como se pode deduzir a partir desses argumentos, uma característica importante dos modelos de equilíbrio geral estocástico dinâmico, na tradição novo-key- 
nesiana, é a relação circular entre as variáveis macroeconômicas relevantes. Isso significa que a dinâmica observada (e/ou prevista), que induz o $\mathrm{BCB}$ a ajustar seus instrumentos de política, é também alterada ou impactada pelas decisões de política monetária. Trata-se de uma dinâmica de múltiplas e recorrentes interações, as quais são gradualmente amortecidas na medida em que as variáveis convirjam para seus valores normais ou potenciais. A Figura 1 mostra de forma ilustrativa essa dinâmica circular.

Figura 1 - Dinâmica circular das variáveis relevantes e das decisões de política monetária

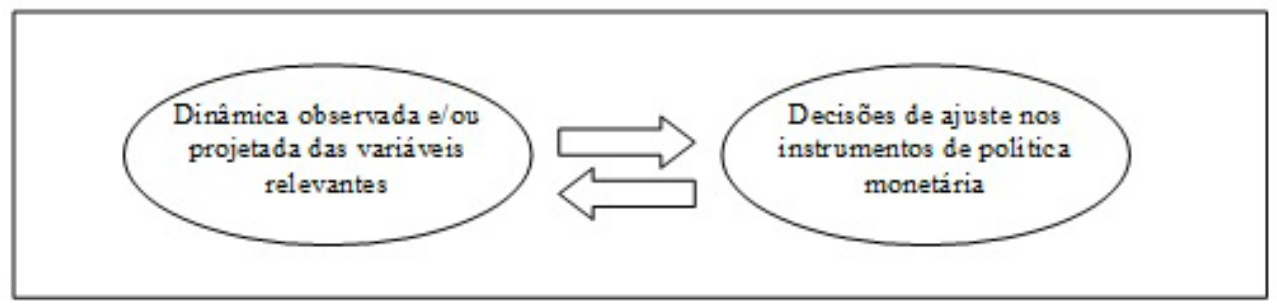

Fonte: Elaboração própria.

Por sua vez, o estudo das respostas regionais face aos ajustes nos instrumentos de política monetária tem sido desenvolvido em muitos países e fornece informações relevantes tanto para a previsão quanto para o planejamento público no que diz respeito ao desenvolvimento de políticas regionais e industriais.

Garrison e Chang (1979), por exemplo, estudaram os ganhos da indústria manufatureira nas oito maiores regiões dos Estados Unidos, no período 1969-1976, e verificaram respostas regionais distintas a partir de mudanças na política monetária, com algumas regiões apresentando maior sensibilidade do que outras. Basicamente, os autores chegaram à conclusão de que as regiões com maior concentração de bens manufaturados foram as que apresentaram maior sensibilidade aos choques monetários, se comparado com aquelas com maior participação dos setores agrícola e de mineração.

Já Carlino e DeFina (1997) pesquisaram sobre a existência de efeitos assimétricos da política monetária norte-americana nos diversos estados do país, ao longo do período 1958-1992, através de modelos autorregressivos estruturais. As funções impulso analisadas demonstraram respostas de renda real diferentes a partir de cada uma das unidades federativas americanas, e diferenças substanciais em certos casos.

Vale ressaltar que Carlino e DeFina (1997) atribuem as respostas estaduais de renda real diferenciadas a três fatores básicos: a) mix industrial; b) tamanho das firmas; c) tamanho dos bancos. Regressões de cross-section, com uso de proxies que tentaram captar os três fatores considerados, revelaram que a porcentagem da indústria manufatureira no PIB estadual possui correlação positiva com a resposta 
local de longo prazo face ao choque monetário, ao passo que a porcentagem das atividades extrativas no PIB possui correlação negativa com a resposta ao impulso monetário. Ou seja, estados com maior peso da indústria manufatureira apresentaram maior sensibilidade às alterações na taxa básica de juros americana, revelando um canal de taxa de juros importante para a política monetária.

Por sua vez, não foram encontradas evidências sobre a correlação entre o tamanho das firmas nos estados e as respostas de longo prazo da renda real aos impulsos monetários. Por outro lado, verificou-se que unidades federativas com maior proporção de bancos de menor porte obtiveram menor sensibilidade aos choques de política monetária.

Da mesma maneira, Arnold e Vrugt (2002) mensuraram os impactos regionais e setoriais da política monetária na Holanda, no período 1973 a 1993, através de vetores autorregressivos com 4 variáveis, 11 regiões, 12 setores e 132 combinações setor-região. Os autores observaram elevada variação nos efeitos produtivos regionais e setoriais a partir dos choques monetários (taxa nominal de juros de curto prazo) e que as diferenças em termos regionais se devem às distintas composições industriais, como ressaltadas pela literatura. Adicionalmente, verificaram que as diferenças de efeitos setoriais, entre os estados, são bastante sensíveis a mudanças na instância de política monetária, em especial no que diz respeito aos setores de construção e de produção industrial, assim como ao setor bancário.

Francis, Owyang e Sekhposyan (2011), por outro lado, testaram os efeitos assimétricos da política monetária americana no nível metropolitano (city-level). Através de uma metodologia de VAR bayesiano, os autores buscaram as origens das assimetrias de respostas das cidades pesquisadas a partir de choques de política monetária e encontraram evidências de que fatores como a densidade populacional, o tamanho do setor público local e a taxa de sindicalização explicam em grande medida as diferentes flutuações do nível de atividade em áreas metropolitanas, ao passo que canais tradicionais na literatura, tais como taxas de juros e crédito, apresentam poder explicativo marginal quando são estudados os efeitos defasados da política monetária.

Os autores argumentam que estudos tradicionais de efeitos regionais da política monetária perdem poder explicativo se comparados com estudos de efeito metropolitano, uma vez que nesses últimos podem ser considerados fatores relevantes que perdem sentido ou não são observados em nível regional ou mesmo estadual.

Vale ressaltar, no entanto, que trabalhos a nível metropolitano partem de uma metodologia e de evidências empíricas que já foram levantadas pelos estudos mais agregados, de certa maneira menos complexos, o que facilita em muito o trabalho para níveis de maior desagregação. 
Logo, para países em que ainda não há evidência robusta a nível estadual ou regional, é razoável dizer que trabalhos ao nível das cidades devem ser realizados mais à frente, após serem coletadas evidências e alcançado know-how a partir de estudos de efeitos mais agregados. Cumpre frisar que esse parece ser o caso da economia capixaba, foco do presente estudo, para a qual ainda não há evidências robustas dos efeitos de política monetária.

\subsection{Os Efeitos Regionais da Política Monetária no Brasil}

No caso brasileiro, Fonseca e Vasconcelos (2003) parecem ser os primeiros a analisar os possíveis efeitos diferenciados da política monetária sobre regiões e estados. Para tanto, utilizaram os canais da taxa de juros e do crédito de transmissão da política monetária, com a análise dividida em duas partes. Na primeira, realizaram um estudo comparativo por meio das conclusões de Carlino e Defina (1997) para os Estados Unidos. Já a segunda etapa consistiu em investigação empírica, por meio de uma estimação VAR com duas defasagens nas variáveis, para dois modelos, objetivando: a) avaliar os impactos por meio da transmissão via canal da taxa de juros; e b) avaliar os impactos através da transmissão via canal do crédito. A principal conclusão a qual os autores chegaram é que os estados das regiões Norte, Nordeste e Centro-Oeste, por terem maior proporção de pequenas empresas e, ao mesmo tempo, por estas serem atendidas por agências e crédito bancário em menor proporção, sofreram maiores impactos de alterações na taxa básica de juros.

Para o Espírito Santo, Fonseca e Vasconcelos (2003) analisaram somente os impactos da política monetária sobre o crédito para o período entre agosto de 1994 e dezembro de 2000, deixando de fora os potenciais impactos dessa política sobre a produção industrial. Assim, a hierarquização do impacto de um desvio padrão na taxa Selic sobre o crédito foi, para todos os períodos considerados (6, 12, 18 e 24 meses), maior no Espírito Santo do que para a média nacional. Outros dados trabalhados pelos autores, como a participação significativa da indústria no PIB estadual e a participação expressiva das pequenas firmas nesse setor, são fatores explicativos para esse impacto negativo superior à média brasileira.

Araújo (2004) produziu outro texto que analisou o impacto regional da política monetária brasileira após o Plano Real, mas restrito às regiões Nordeste e Sul, usando a metodologia VAR. A diferença entre esse trabalho e o de Fonseca e Vasconcelos (2003) é a consideração de um sistema VAR para cada estado/região. Procurou avaliar quantitativamente o grau de assimetria em termos das respostas dos índices de produção industrial das respectivas regiões a um choque de política monetária: a) as respostas para as duas regiões em termos agregados são bastante assimétricas, pois o Sul tende a reagir mais fortemente ao choque que o Nordeste; b) o impacto em nível estadual foi também bastante assimétrico; c) apesar dos 
estados do Sul serem mais afetados relativamente do que os estados nordestinos, Bahia e Pernambuco reagem fortemente ao choque em comparação com o Nordeste como um todo.

O trabalho de Chumvichitra (2004), usando da mesma técnica empregada por Araújo (2004) de multissistemas de VAR, investigou as diferenças dos efeitos de transmissão monetária sobre as rendas regionais, além de identificar eventuais assimetrias entre os setores produtivos de cada região. Os resultados encontrados mostraram que os choques de política monetária atingem mais severamente as regiões Sudeste, Sul e Centro-Oeste. Setorialmente, o choque monetário impacta mais o nível de atividades de setores cuja participação é relevante para o produto agregado de cada localidade em questão. A principal restrição desse artigo, conforme Rocha (2007), é a falta de graus de liberdade originada pela base de dados anuais com 15 observações.

Rocha (2007), por outro lado, estudou a assimetria da política monetária para alguns estados selecionados (São Paulo, Minas Gerais, Rio de Janeiro, Rio Grande do Sul, Paraná, Bahia e Pernambuco) usando o modelo de fatores dinâmicos generalizado, desenvolvido por Forni et al. (2004, 2000), e tomando como guia o texto de Sala (2002). As principais conclusões foram: a) a existência de assimetrias nos efeitos deste choque comum; e b) os estados da Bahia e do Paraná aparecem como sendo os mais vulneráveis, enquanto São Paulo, Pernambuco e Minas Gerais seriam os menos afetados pela política monetária. No entendimento do referido autor, o ordenamento obtido para as respostas estaduais pode ser devido à existência de um canal de crédito mais ativo entre os estados mais afetados pela política monetária. Segundo o mesmo autor, essas unidades contam com uma estrutura bancária mais restrita quanto ao oferecimento de crédito, além de uma concentração de firmas potencialmente mais sujeitas a problemas de informação.

Já Bertanha e Haddad (2008) estimaram os efeitos da política monetária na atividade dos estados do Brasil, bem como analisaram as diferenças nos efeitos. Basearam-se em um modelo estrutural espacial de vetores autorregressivos (SVAR), apresentado por Di Giacinto (2003), e em técnicas da econometria espacial, o que tornou possível incorporar séries de todos os estados em um mesmo sistema e, ainda assim, possuir graus de liberdade para a estimação adequada. A grande contribuição do estudo é que inclui uma variável de atividade econômica para todas as unidades da federação, o que evita o enviesamento do resultado causado pela não consideração do efeito transbordamento do choque de seus vizinhos, dada a importância do comércio interestadual, o que os estudos citados anteriormente não fizeram.

Com uma base de dados para o período de janeiro de 1995 a dezembro de 2005 e usando o nível de emprego como proxy para atividade econômica, os autores identificaram que os estados das regiões Norte e Nordeste são os mais sensíveis 
a choques de política monetária. No caso do Espírito Santo, foi o sétimo mais afetado pelo aumento da taxa Selic no período estudado.

Por sua vez, Fonseca e Medeiros (2011) analisaram os impactos da política monetária na produção e no crédito de estados brasileiros selecionados no período pós-regime de metas de inflação. Para isso, estimaram modelos VAR para o Brasil e para cada estado selecionado. A partir de funções de impulso-resposta (FIR), verificou-se que um aumento de um desvio padrão (3,5 p. p.) na taxa Selic causa queda diferenciada na produção, dos estados brasileiros, ao longo de 24 períodos, bem como no Brasil. O estado com maior queda foi São Paulo $(-1,05 \%)$ e o com menor foi Minas Gerais (-0,33\%). Sobre o crédito, os estados da Região Sul foram os menos afetados, com queda média de $0,80 \%$, mas com reação mais rápida. Minas Gerais e Ceará tiveram queda maior do que a média do Brasil (-1,55\%).

Acerca do Espírito Santo, Fonseca e Medeiros (2011), descobriram que um aumento de um desvio padrão na Selic provoca uma queda de $0,89 \%$ na produção industrial, maior que a do Brasil (-0,574\%). Quanto à oferta de crédito, uma política monetária restritiva impactou negativamente mais o estado $(-1,65 \%)$ do que o país (-1,55\%).

Por fim, Rocha et al. (2011) examinam os diferentes efeitos da política monetária sobre alguns estados brasileiros. Uma análise das funções de resposta a impulso, extraídas de modelos SVAR, aponta para assimetrias nas respostas dos produtos estaduais a choques monetários. A segunda parte investiga quais características estaduais poderiam explicar tais assimetrias com base em um modelo de regressão. A evidência sugere que a intensidade da resposta do produto estadual é relacionada diretamente às variáveis de composição industrial, ao grau de abertura e ao volume de crédito, os quais dão suporte aos canais de transmissão da taxa de juros e de crédito da política monetária.

\section{Características da Economia no Espírito Santo}

De maneira geral, o Espírito Santo é considerado um estado de pequeno porte dentro do contexto federativo brasileiro, dado que representava 2,1\% do PIB nacional e 1,8\% da população brasileira em 2010 (IBGE, 2013).

Quanto à estrutura produtiva capixaba, as atividades terciárias predominam com $57,7 \%$ do PIB local, seguido da indústria (36,0\%) e da agricultura (6,3\%). Conforme descrito por Caçador e Grassi (2009), no primeiro caso são importantes as atividades de comércio varejista, setor público e serviços de transporte, logística e armazenagem ligados ao comércio exterior. Já na indústria, a produção de commodities respondia por $76,6 \%$ do valor da transformação industrial (VTI) e por 92,5\% das exportações do estado. Por fim, a cafeicultura é sua atividade agrícola mais relevante. 
Em função dessas características (mercado consumidor relativamente pequeno e grandes plantas industriais exportadoras), a economia capixaba possui outras duas peculiaridades: uma participação muito forte no comércio internacional e no comércio inter-regional em sua economia. No primeiro caso, por exemplo, Magalhães e Toscano (2009) mostraram, para o período entre o primeiro semestre de 2004 e o segundo semestre de 2009 , que o grau de abertura estimado para o estado equivale, em média, a $49 \%$, cerca de duas vezes maior que o do país.

Porém, esse elevado grau de interdependência com outras regiões e países tem um efeito colateral considerável, qual seja, uma maior volatilidade de sua atividade econômica em comparação à média nacional. No caso do comércio inter-regional, Magalhães e Ribeiro (2010), que estudaram as propriedades quantitativas dos ciclos de negócios ocorridos no Espírito Santo desde a década de 1990, demonstraram, entre outras coisas, que: a) as flutuações cíclicas no nível de atividade estadual são nitidamente mais voláteis do que as variações ocorridas no caso brasileiro; e b) o estado apresenta forte grau de co-movimento com o índice de atividade do país, assim como com alguns estados das Regiões Sul e Sudeste.

Do lado externo, Magalhães (2010) mensurou empiricamente os efeitos de variações nos preços de commodities sobre o nível de atividade do Espírito Santo. Dentre os resultados obtidos, destaca-se que, por conta de seu alto grau de abertura, o estado sente mais intensamente os impactos de choques nesses preços do que o Brasil e outras regiões. Em outras palavras, uma elevação desses preços tende a beneficiar mais a economia capixaba do que a nacional, e o mesmo ocorre quando do contrário: reduções nos preços de commodities fazem a economia capixaba apresentar desaceleração em maior magnitude do que no caso nacional.

Em relação ao objetivo do presente trabalho, que é analisar o impacto da política monetária sobre a economia capixaba, não se encontrou, até então, nenhum estudo na literatura local que trate desse tema. O texto de Magalhães et al. (2009), cujo objetivo é verificar o efeito quantitativo de eventos que tendem a acentuar o grau de incerteza e a taxa de juros no nível de atividade por meio de um índice de incerteza agregada, é o que mais se aproxima do referido tema. Nesse sentido, os resultados demonstraram que aumentos na incerteza e nos juros causam um efeito contracionista sobre a atividade econômica no curto prazo, com a economia apresentando uma recuperação ao nível inicial de equilíbrio apenas após diversos meses. Os resultados revelam também diferenças consideráveis nas respostas dinâmicas de distintas unidades da federação, bem como de setores específicos da economia capixaba, tanto em termos de volatilidade quanto em termos da recuperação em resposta aos choques macroeconômicos considerados.

Dessa maneira, partindo da contribuição seminal de Carlino e Defina (1997), e atualizando alguns dados de Fonseca e Vasconcelos (2003), são apresentadas algumas estatísticas descritivas que permitem mapear os estados mais afetados pela 
política monetária no Brasil. Do ponto de vista da atividade econômica, Carlino e Defina (1997) afirmam que a concentração produtiva em algumas regiões torna as mesmas mais suscetíveis a oscilações via aumento da taxa de juros. Dessa forma, como mostra a Tabela 1, os estados do Sul e do Sudeste (com exceção do Espírito Santo), a Bahia e o Distrito Federal seriam os mais afetados por choques de política monetária, dado que em conjunto representam quase $80 \%$ do PIB nacional.

Tabela 1 - Participação (\%) dos estados no PIB nacional (média entre 2000 e 2010)

\begin{tabular}{lc|lc}
\hline Estado & $\%$ & Estado & $\%$ \\
\hline São Paulo & 34,07 & Amazonas & 1,52 \\
Rio de Janeiro & 11,36 & Maranhão & 1,14 \\
Minas Gerais & 8,93 & Mato Grosso do Sul & 1,06 \\
Rio Grande do Sul & 6,86 & Rio Grande do Norte & 0,83 \\
Paraná & 5,98 & Paraíba & 0,83 \\
Bahia & 4,07 & Alagoas & 0,66 \\
Santa Catarina & 3,91 & Sergipe & 0,62 \\
Distrito Federal & 3,84 & Rondônia & 0,57 \\
Goiás & 2,45 & Piauí & 0,53 \\
Pernambuco & 2,35 & Tocantins & 0,41 \\
Espírito Santo & 2,07 & Amapá & 0,21 \\
Ceará & 1,95 & Acre & 0,21 \\
Pará & 1,82 & Roraima & 0,16 \\
Mato Grosso & 1,58 & Brasil & 100,00 \\
\hline
\end{tabular}

Fonte: IBGE (2013).

Ainda segundo Carlino e Defina (1997), a análise da transmissão monetária, através do canal do crédito, estabelece que as empresas pequenas e dependentes de empréstimos bancários teriam maior sensibilidade a mudanças na política monetária. Caso houvesse uma elevação na taxa de juros, os empréstimos bancários diminuiriam devido à menor quantidade de reservas bancárias e menor capacidade das instituições bancárias em oferecer crédito, além da assimetria de informações, que proporcionaria uma seletividade maior na concessão de crédito, atendendo àquelas empresas de maior equilíbrio patrimonial e com projetos de menor risco. Nessa ótica, os estados do Sul, Sudeste (com exceção do Rio de Janeiro), Centro-Oeste (com exceção do Distrito Federal) e Roraima seriam os mais afetados por políticas monetárias restritivas, conforme a Tabela 2 . 
Tabela 2 - Classificação dos estados pelo percentual (\%) de MPE's segundo pessoal ocupado (média entre 2000 e 2009 das empresas com menos de 50 empregados)

\begin{tabular}{ll|lc}
\hline Estado & $\%$ & Estado & $\%$ \\
\hline Mato Grosso & 51,5 & Pernambuco & 35,3 \\
Paraná & 51,3 & Ceará & 35,1 \\
Santa Catarina & 49,8 & Paraíba & 34,8 \\
Rio Grande do Sul & 48,9 & Pará & 34,1 \\
Mato Grosso do Sul & 47,7 & Amapá & 34,1 \\
Espírito Santo & 47,4 & Maranhão & 34,1 \\
Goiás & 46,6 & Piauí & 33,6 \\
Minas Gerais & 46,3 & Sergipe & 32,6 \\
Roraima & 42,5 & Tocantins & 31,3 \\
São Paulo & 42,0 & Acre & 30,4 \\
Bahia & 40,8 & Alagoas & 27,5 \\
Rio de Janeiro & 40,5 & Distrito Federal & 23,6 \\
Rondônia & 37,2 & Amazonas & 21,7 \\
Rio Grande do Norte & 37,0 & Brasil & 41,6 \\
\hline
\end{tabular}

Fonte: IBGE (2011).

Além da distribuição espacial da atividade econômica, Carlino e Defina (1997) analisaram a distribuição do crédito entre as unidades federativas. O argumento é que as regiões com maior participação no crédito tendem a ser mais afetadas por políticas monetárias restritivas em função da redução de sua oferta. Sob essa perspectiva, estados cuja produção apresente maior intensidade em crédito são justamente os que possuiriam maior sensibilidade a políticas da autoridade monetária que tenham como efeito o encarecimento nas linhas de liquidez e crédito. Assim, a Tabela 3 mostra que São Paulo, Rio de Janeiro, Distrito Federal, Minas Gerais, Rio Grande do Sul e Paraná seriam os mais afetados por um possível aumento nos juros. 
Tabela 3 - Participação (\%) dos estados no crédito do Brasil (média entre 2000 e 2010)*

\begin{tabular}{lc|lc}
\hline Estado & $\%$ & Estado & $\%$ \\
\hline São Paulo & 56,0 & Pará & 0,6 \\
Rio de Janeiro & 7,5 & Maranhão & 0,5 \\
Distrito Federal & 6,0 & Paraíba & 0,4 \\
Minas Gerais & 5,6 & Rio Grande do Norte & 0,4 \\
Rio Grande do Sul & 5,5 & Alagoas & 0,3 \\
Paraná & 4,8 & Piauí & 0,3 \\
Santa Catarina & 2,1 & Amazonas & 0,3 \\
Bahia & 2,0 & Sergipe & 0,3 \\
Goiás & 1,7 & Rondônia & 0,2 \\
Pernambuco & 1,4 & Tocantins & 0,2 \\
Mato Grosso & 1,2 & Roraima & 0,1 \\
Ceará & 1,0 & Acre & 0,1 \\
Espírito Santo & 0,9 & Amapá & 0,1 \\
Mato Grosso do Sul & 0,8 & Brasil & 100,0 \\
\hline
\end{tabular}

Fonte: BCB (2011).

Nota: * Crédito com base nas estatísticas bancárias municipais, saldo de dezembro de cada ano.

Outra variável utilizada para se avaliar o canal de distribuição do crédito entre as unidades federativas é por meio da distribuição geográfica das agências e postos bancários. A Tabela 4 aponta que os estados do Sudeste (com exceção do Espírito Santo) e do Sul e a Bahia concentravam a grande maioria da atividade bancária do país. Essa informação ratifica a da Tabela 3, pois os maiores grupos bancários tendem a atuar perto de sua sede operacional (CECHETTI, 1999). Pode-se, ainda, argumentar que regiões cuja produção é mais intensiva em crédito são justamente as que acabam por viabilizar maior escala de agências e postos bancários. 
Tabela 4 - Distribuição das agências e postos bancários (\%) entre os estados (dez./2010)

\begin{tabular}{lc|lc}
\hline Estado & $\%$ & Estado & $\%$ \\
\hline São Paulo & 30,8 & Mato Grosso & 1,6 \\
Minas Gerais & 10,1 & Amazonas & 1,5 \\
Rio de Janeiro & 8,3 & Paraíba & 1,4 \\
Rio Grande do Sul & 7,4 & Mato Grosso do Sul & 1,4 \\
Paraná & 6,4 & Rio Grande do Norte & 1,3 \\
Bahia & 5,0 & Piauí & 1,0 \\
Santa Catarina & 4,4 & Alagoas & 0,9 \\
Goiás & 3,0 & Tocantins & 0,8 \\
Pernambuco & 2,7 & Sergipe & 0,8 \\
Distrito Federal & 2,3 & Rondônia & 0,6 \\
Ceará & 2,1 & Amapá & 0,3 \\
Pará & 1,9 & Acre & 0,3 \\
Espírito Santo & 1,8 & Roraima & 0,2 \\
Maranhão & 1,8 & Brasil & 100,0 \\
\hline
\end{tabular}

Fonte: BCB (2011).

Dessa forma, no caso do Espírito Santo, tomando como base Carlino e Defina (1997), a única variável que torna seu nível de atividade mais vulnerável a aumentos da taxa de juros é a importância dos pequenos negócios para sua economia. Contudo, a teoria econômica diz também que a política monetária restritiva tende a provocar uma valorização cambial em função do crescimento da entrada de capitais (MOREIRA, 2011). Ora, esse fator tem que ser levado em conta, portanto, para uma economia com alto grau de abertura como a capixaba, conforme citado anteriormente. O impacto da política monetária no comércio exterior e em outros indicadores do nível de atividade de uma pequena economia aberta, a capixaba nesse caso, será mais precisamente analisado nas seções 4 e 5 , utilizando a metodologia de VAR.

\section{Procedimentos Empíricos}

\subsection{Vetores Autorregressivos (VAR) ${ }^{2}$}

Pode-se expressar um modelo $\mathrm{VAR}^{3}$ de ordem $p$ em função de um vetor com $n$ variáveis endógenas, $X_{t}$, sendo que estas se conectam por meio de uma matriz $A$, da seguinte forma:

$$
A X_{t}=B_{o} \sum_{i=1}^{p} B_{i} X_{t-i}+B \varepsilon_{t}
$$

$2 \quad$ Metodologia desenvolvida inicialmente por Sims (1980).

3 A metodologia VAR descrita aqui está baseada em Bueno (2008). 
Em que:

$A$ é uma matriz $n x n$ que define as restrições contemporâneas entre as variáveis que constituem o vetor $n x 1, X_{t}$;

$B_{0}$ é o vetor de constantes ;

$B_{i}$ são as matrizes $n \times n$;

$B$ é a matriz diagonal $n x n$ de desvios-padrão; e,

$\varepsilon_{t}$ é o vetor de $n x 1$ perturbações aleatórias não correlacionadas entre si contemporânea ou temporalmente, isto é:

$$
\varepsilon_{t} \sim \text { i.i.d }\left(0 ; I_{n}\right)
$$

A equação 1 expressa as relações entre as variáveis endógenas, geralmente advindas de um modelo econômico teoricamente estruturado, e é denominada de forma estrutural. No entanto, devido à endogeneidade das variáveis do VAR, o modelo é normalmente estimado em sua forma reduzida, dada por:

$$
\begin{aligned}
& X_{t}=A^{-1} B_{0}+\sum_{i=1}^{p} A^{-1} B_{i} X_{t-i}+A^{-1} B \varepsilon_{t}=\Phi_{0}+\sum_{i=1}^{p} \Phi_{i} X_{t-i}+e_{t}, \\
& \text { em que } \Phi_{i}=A^{-1} B_{i}, i=0,1,2, \ldots, p \text { e } B \varepsilon_{t}=A e_{t}
\end{aligned}
$$

A metodologia VAR pode ser estimada por meio do método de mínimos quadrados ordinários (MQO), levando-se em conta, principalmente, a interação entre as variáveis do sistema considerado. Entre as suas principais vantagens na análise econométrica, estão a obtenção das funções de impulso-resposta (FRI) e a decomposição da variância (DV).

\subsection{Variáveis e Dados}

Este estudo compreende o período entre janeiro de 2000 e dezembro de 2010 , abrangendo a fase pós-adoção do sistema de metas para a inflação no Brasil. O Quadro 1 sintetiza as variáveis utilizadas no estudo e as respectivas fontes dos dados.

As variáveis M4, CESTBASICA, CREDITOES, ICMSES, CREDITOBR e ICMSBR foram deflacionadas pelo IPCA. Os índices utilizados tomam como base o mês de janeiro de 2000. As séries referentes à EMPREGOES, EMPREGOBR, PRODINDES e PRODINDBR foram utilizadas em suas formas dessazonalizadas, disponibilizadas pelo IBGE. No mais, testou-se a presença de sazonalidade nas demais séries pelo teste combinado para a presença de sazonalidade, identificável na rotina de dessazonalização X12 do US Census Bureau. Aquelas que apresentaram sazonalidade foram dessazonalizadas pelo mesmo método. Todas as análises foram realizadas com as séries expressas em logaritmos naturais. 
Quadro 1 - Variáveis, unidades, siglas e fontes (jan./2000-dez./2010)

\begin{tabular}{|c|c|c|c|}
\hline Variável & Unidade & Sigla & Fonte \\
\hline Agregado monetário & $\mathrm{R} \$$ milhões & M4 & Bacen \\
\hline Taxa de juros nominal de curto prazo - Selic Over & $\%$ & TXJUROS & Bacen \\
\hline $\begin{array}{c}\text { Taxa de câmbio efetiva real - deflacionada pelo } \\
\text { IPA-OG - dessazonalizada pelo método X12 (US } \\
\text { Census Bureau) }\end{array}$ & Índice & TXCAMBIO & Ipeadata \\
\hline Índice Nacional de Preços ao Consumidor Amplo & Índice & IPCA & IBGE \\
\hline $\begin{array}{c}\text { Cesta básica no município de Vitória - } \\
\text { dessazonalizada pelo método X12 (US Census } \\
\text { Bureau) }\end{array}$ & $\mathrm{R} \$ 1,00$ & CESTBASICA & Dieese \\
\hline $\begin{array}{c}\text { Quantum exportado pelo Espírito Santo - } \\
\text { dessazonalizada pelo método X12 (US Census } \\
\text { Bureau) }\end{array}$ & $\mathrm{kg}$ & EXPORTES & Secex \\
\hline $\begin{array}{c}\text { Quantum importado pelo Espírito Santo - } \\
\text { dessazonalizada pelo método X12 (US Census } \\
\text { Bureau) }\end{array}$ & $\mathrm{kg}$ & IMPORTES & Secex \\
\hline Emprego formal do Espírito Santo & Índice & EMPREGOES & MTE \\
\hline Produção industrial mensal do Espírito Santo & Índice & PRODINDES & IBGE \\
\hline Volume das operações de crédito no Espírito Santo & $\mathrm{R} \$$ milhões & CREDITOES & Bacen \\
\hline $\begin{array}{c}\text { Arrecadação do ICMS no Espírito Santo - } \\
\text { dessazonalizada pelo método X12 (US Census } \\
\text { Bureau) }\end{array}$ & $\mathrm{R} \$$ milhões & ICMSES & $\begin{array}{l}\text { Min. Fazenda } \\
\text { - Cotepe }\end{array}$ \\
\hline $\begin{array}{l}\text { Quantum exportado pelo Brasil - dessazonalizada } \\
\text { pelo método X12 (US Census Bureau) }\end{array}$ & $\mathrm{kg}$ & EXPORTBR & Secex \\
\hline $\begin{array}{l}\text { Quantum importado pelo Brasil - dessazonalizada } \\
\text { pelo método X12 (US Census Bureau) }\end{array}$ & $\mathrm{kg}$ & IMPORTBR & Secex \\
\hline Emprego formal do Brasil & Índice & EMPREGOBR & MTE \\
\hline Produção industrial mensal do Brasil & Índice & PRODINDBR & IBGE \\
\hline Volume das operações de crédito no Brasil & $\mathrm{R} \$$ milhões & CREDITOBR & Bacen \\
\hline $\begin{array}{l}\text { Arrecadação do ICMS no Brasil - dessazonalizada } \\
\text { pelo método X12 (US Census Bureau) }\end{array}$ & $\mathrm{R} \$$ milhões & ICMSBR & $\begin{array}{l}\text { Min. Fazenda } \\
\text { - Cotepe }\end{array}$ \\
\hline
\end{tabular}

Fonte: Elaboração própria. 


\section{Resultados}

Este item está dividido em quatro partes: a primeira será destinada a realização dos testes de raiz unitária. Na segunda, apresenta-se a identificação do modelo VAR ideal para a economia do Espírito Santo. Logo após, demonstram-se os resultados referentes à identificação do modelo VAR para a economia do Brasil. Por fim, apresentam-se as FIR das economias capixaba e brasileira, tentando fazer uma comparação entre as mesmas.

\subsection{Testes de RaizUnitária}

Para verificar a estacionariedade das séries, foram realizados os seguintes testes de

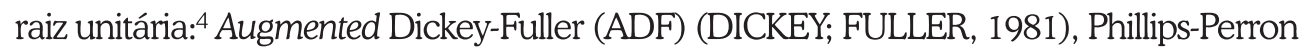
(PP) (PHILLIPS; PERRON, 1988) e Kwiatkowski-Phillips-Schmidt-Shin (KPSS) (KWIATKOWSKI et. al., 1992)..$^{5}$ Os resultados podem ser verificados na Tabela 5. Pela análise dos testes estabelecidos, verificou-se que as seguintes variáveis são estacionárias em nível: EXPORTES, IMPORTES, PRODINDES, EXPORTBR, IMPORTBR e PRODINDBR. Já as variáveis M4, TXJUROS, TXCAMBIO, IPCA, CESTBASICA, EMPREGOES, CREDITOES, ICMSES, EMPREGOBR, CREDITOBR e ICMSBR mostraram-se não estacionárias em nível. Em primeira diferença, estas variáveis tornaram-se estacionárias.

Nota-se que existe certa ambiguidade nos testes realizados, além do que a ordem de integração das variáveis é diferente. Nesse contexto, vale destacar que a hipótese básica do modelo é que as séries sejam estacionárias. Entretanto, não existe um consenso na literatura no que se refere a trabalhar com as variáveis no modelo VAR em nível e/ ou em primeira diferença. Sims (1980) e Sims, Stock e Watson (1990), por exemplo, não veem maiores problemas em se trabalhar com variáveis estacionárias e não estacionárias em um modelo VAR, uma vez que é uma metodologia que está interessada nas inter-relações entre as variáveis. Isso é alcançado por meio de um VAR completo, com as variáveis tomadas em nível. No mais, Sims, Stock e Watson (1990) demonstraram que para modelos autorregressivos, os resultados de testes em nível são consistentes assintoticamente, e que a transformação das variáveis para a sua primeira diferença, os testes de cointegração e a aplicação do mecanismo de correção de erros (MCE) tornam-se desnecessários. ${ }^{6}$ Sendo assim, as análises serão realizadas com as variáveis em nível.

$4 \quad$ Nos testes ADF e PP a hipótese nula equivale à existência de uma raiz unitária na série de dados. Já no teste KPSS, a hipótese nula refere-se à estacionariedade da série.

$5 \quad$ Vale ressaltar que o teste KPSS é um teste assintótico e que deve ser utilizado em complemento aos demais testes de raiz unitária (BUENO, 2008). Assim, as conclusões sobre a existência de raiz unitária foram feitas primeiramente tomando como base os testes ADF e PP, e em caso de divergência entre os testes ADF e PP, utilizou-se o teste KPSS como critério de desempate. Para critério de desempate também foi analisado o correlograma (função de autocorrelação) da série em questão.

6 Tomazzia e Meurer (2009) salientam que a ideia de não trabalhar com a análise de cointegração vem sendo adotada por diversos estudos de economia, a saber: Bernanke e Gertler (1995) (EUA), Dedola e Lippi (2005) (países desenvolvidos) e Céspedes et al. (2008) (Brasil). 
No próximo item serão apresentadas as estimativas relativas à identificação do modelo VAR. ${ }^{7}$ Como o objetivo deste trabalho é verificar, principalmente, o impacto das variáveis de política monetária sobre algumas variáveis das economias do Espírito Santo e do Brasil, a análise será dividida em dois modelos.

Tabela 5 - Testes de raiz unitária para as variáveis em nível

\begin{tabular}{lcccccc}
\hline \multicolumn{1}{c}{ Variável } & ADF & K & PP & K & KPSS & K \\
\hline LM4 & $-1,902645 \mathrm{~ns}$ & 3 & $-1,334853 \mathrm{~ns}$ & 8 & $0,298680^{* * *}$ & 9 \\
LTXJUROS & $-2,569243 \mathrm{~ns}$ & 12 & $-3,432843^{*}$ & 3 & $0,198709 * *$ & 9 \\
LTXCAMBIO & $-2,876639 \mathrm{~ns}$ & 1 & $-2,817066 \mathrm{~ns}$ & 3 & $0,146354^{* *}$ & 9 \\
LIPCA & $-1,770436 \mathrm{~ns}$ & 1 & $-1,761711 \mathrm{~ns}$ & 8 & $0,293783^{* * *}$ & 9 \\
LCESTBASICA & $0,315445 \mathrm{~ns}$ & 4 & $-3,096976 * *$ & 34 & $0,278331^{* * *}$ & 9 \\
LEXPORTES & $-10,22880^{* * *}$ & 0 & $-10,63849 * * *$ & 6 & $0,168384 * *$ & 7 \\
LIMPORTES & $-11.06150 * * *$ & 0 & $-11.08199 * * *$ & 2 & $0,079747 \mathrm{~ns}$ & 1 \\
LEMPREGOES & $-2,813160 \mathrm{~ns}$ & 12 & $-0,998552 \mathrm{~ns}$ & 8 & $0,171432 * *$ & 9 \\
LPRODINDES & $-3,025388^{* * *}$ & 0 & $-3,243522^{*}$ & 4 & $0,082156 \mathrm{~ns}$ & 9 \\
LCREDITOES & $-1,620086 \mathrm{~ns}$ & 1 & $-1,646025 \mathrm{~ns}$ & 1 & $0,315094 * * *$ & 9 \\
LICMSES & $-2,401697 \mathrm{~ns}$ & 2 & $-6,224052 * * *$ & 5 & $0,152212^{* *}$ & 8 \\
LEXPORTBR & $-9,384893 * *$ & 0 & $-9,352772 * * *$ & 4 & $0,196018 \mathrm{~ns}$ & 5 \\
LIMPORTBR & $-3,101148 \mathrm{~ns}$ & 1 & $-9,537395^{* * *}$ & 5 & $0,086340 \mathrm{~ns}$ & 8 \\
LEMPREGOBR & $-2,451318 \mathrm{~ns}$ & 14 & $-2,715407 \mathrm{~ns}$ & 2 & $0,226489 * *$ & 9 \\
LPROINDBR & $-3,311889 *$ & 1 & $-3,055685 \mathrm{~ns}$ & 1 & $0,092191 \mathrm{~ns}$ & 8 \\
LCREDITOBR & $-1,346276 \mathrm{~ns}$ & 0 & $-1,343526 \mathrm{~ns}$ & 1 & $0,337297 * * *$ & 9 \\
LICMSBR & $-2,185975 \mathrm{~ns}$ & 1 & $-2,594854 \mathrm{~ns}$ & 2 & $0,263229 * *$ & 9 \\
\hline
\end{tabular}

Fonte: Elaboração própria.

Nota: 1) ** * Significativo a 1\%; * Significativo a 5\%; * Significativo a 10\%; ns: Não significativo a $10 \%$ (em estatística, não significativo refere-se a não rejeitar a hipótese nula); 2) K: número de defasagens de cada teste para cada variável; 3) L: indica que as variáveis estão expressas em logaritmos.

\subsection{Identificação do Modelo VAR para a Economia do Espírito Santo}

Este modelo trabalhou com as séries M4, TXJUROS, TXCAMBIO, CESTABASICA, EXPORTES, IMPORTES, EMPREGOES, PRODINDES, CREDITOES e ICMSES. ${ }^{8}$ Com o intuito de selecionar o modelo VAR ideal para representar a economia capixaba, adotaram-se, inicialmente, os critérios da razão de verossimilhança (LR), do erro de previsão final (FPE), de Akaike (AIC), de Schwarz (SC) e de Hannan-Quinn (HQ) para selecionar o número de defasagens a ser empregado. Como

Realizaram-se os testes de Chow, Cusum e de resíduos recursivos e não foram detectadas quebras estruturais nos modelos estimados.

8 Além das variáveis descritas, o modelo foi estimado com uma constante (variável exógena) e uma variável exógena dummy (variável binária) para a variável EXPORTES (variável com um dos piores resultados de normalidade) no mês de junho de 2002. Essa observação apresentou valor muito inferior às demais observações para a variável em questão. Também foram inclusas como variáveis exógenas: índice de risco-país EMBI+ Brasil (JPMorgan) e commodity price index (FMI). 
pode ser observado na Tabela 6, pelos critérios estabelecidos o modelo adequado deve possuir duas defasagens.

Ainda em relação à adequação do modelo, foram realizados os seguintes testes: a) análise do padrão das raízes do polinômio estimado; b) teste de Breusch Godfrey (BG) ou Teste LM: para verificar se existe autocorrelação dos resíduos; c) teste de heterocedasticidade; e d) teste de normalidade dos resíduos de Jarque-Bera (JB). O modelo com duas defasagens apresentou todas as raízes dentro do círculo unitário, satisfazendo a condição de estabilidade do VAR. Os resultados foram satisfatórios para não autocorrelação (foram utilizadas quatro defasagens) e também para ausência de heterocedasticidade.

Tabela 6 - Determinação do número de defasagens do modelo VAR para o Espírito Santo

\begin{tabular}{cccccc}
\hline Defasagem & LR & FPE & AIC & SC & HQ \\
\hline 0 & - & $3,64 \mathrm{E}-21$ & $-18,6825$ & $-17,7912$ & $-18,3204$ \\
1 & 1729,561 & $4,52 \mathrm{E}-27$ & $-32,2916$ & $-29,17216^{*}$ & $-31,02414^{*}$ \\
2 & $181,4816^{*}$ & $3,90 \mathrm{e}-27^{*}$ & $-32,47409^{*}$ & $-27,1265$ & $-30,3014$ \\
3 & 120,6169 & $5,62 \mathrm{E}-27$ & $-32,1947$ & $-24,619$ & $-29,1167$ \\
4 & 116,3566 & $7,89 \mathrm{E}-27$ & $-32,0174$ & $-22,2136$ & $-28,0341$ \\
\hline
\end{tabular}

Fonte: Elaboração própria.

Nota: 1) "Indica a ordem selecionada pelo critério; 2) LR: razão de verossimilhança; FPE: erro de previsão final; AIC: Akaike; SC: Schwarz; HQ: Hannan-Quinn.

No que tange ao teste de normalidade dos resíduos, o teste de Jarque-Bera rejeitou a hipótese nula de que os resíduos são normais. Entretanto, uma vez que não há possibilidade de elevar o tamanho da amostra, devido à escassez de dados anteriores ao ano de 2000 para a economia do Espírito Santo, e tendo em vista os possíveis problemas que a ausência dessa hipótese pode causar para o modelo, desconsiderou-se tal hipótese, continuando com a estimação do modelo em questão. Destaca-se que Oreiro et al. (2006) salientam que esse procedimento é comum em alguns trabalhos no Brasil, como os de Grôppo (2004) e Camuri (2005).

\subsection{Identificação do Modelo VAR para a Economia Brasileira}

Este modelo contou com as variáveis: M4, TXJUROS, TXCAMBIO, IPCA, EXPORTBR, IMPORTBR, EMPREGOBR, PROINDBR, CREDITOBR e ICMSBR. ${ }^{9}$ Os critérios de informação sugeriram a utilização de quatro defasagens (Tabela 7). Os resultados foram satisfatórios para não autocorrelação (foram utilizadas quatro defasagens). Além disso, constatou-se a não heterocedasticidade dos resíduos. Quanto à normalidade dos erros, adotou-se o mesmo critério estabelecido para o modelo referente à economia do Espírito Santo.

Além das variáveis descritas, o modelo foi estimado as seguintes variáveis exógenas: constante, índice de risco-país EMBI+ Brasil (JPMorgan) e commodity price index (FMI). 
Tabela 7 - Determinação do número de defasagens do modelo VAR para o Brasil

\begin{tabular}{cccccc}
\hline Defasagem & LR & FPE & AIC & SC & HQ \\
\hline 0 & - & $8,69 \mathrm{E}-26$ & $-29,3266$ & $-28,6581$ & $-29,055$ \\
1 & 2138,708 & $3,50 \mathrm{E}-33$ & $-46,3615$ & $-43,46493^{*}$ & $-45,18462^{*}$ \\
2 & 257,5891 & $1,48 \mathrm{E}-33$ & $-47,2523$ & $-42,1275$ & $-45,17$ \\
3 & 176,1157 & $1,20 \mathrm{E}-33$ & $-47,5436$ & $-40,1907$ & $-44,5561$ \\
4 & $146,4441^{*}$ & $1,19 \mathrm{e}-33^{*}$ & $-47,70397^{*}$ & $-38,1229$ & $-43,8112$ \\
\hline
\end{tabular}

Fonte: Elaboração própria.

Nota: 1) * Indica a ordem selecionada pelo critério; 2) LR: razão de verossimilhança; FPE: erro de previsão final; AIC: Akaike; SC: Schwarz; HQ: Hannan-Quinn.

\subsection{Funções Impulso-Resposta para as Economias do Espírito Santo e do Brasillo}

Finalizada a etapa identificação do modelo, serão analisadas as funções de impulso-resposta, muito utilizadas em trabalhos que adotam a metodologia VAR. Ressalta-se que, antes de estimar as funções de impulso-resposta, é fundamental identificar o ordenamento de Cholesky do modelo VAR, um dos métodos mais populares para tal finalidade, pois as funções de impulso-resposta são sensíveis à ordenação das variáveis. Esta pesquisa adotou, como método de ordenação das variáveis, o de informação a priori (teoria econômica, conhecimento do mercado, artigos, entre outros). ${ }^{11}$ A ordenação adotada para economia do Espírito Santo foi: TXJUROS, M4, CREDITOES, TXCAMBIO, EMPREGOES, PROINDES, EXPORTES, IMPORTES, CESTABASICA e ICMSES. Em relação à economia brasileira, utilizou-se a ordenação: TXJUROS, M4, CREDITOBR, TXCAMBIO, EMPREGOBR, PROINDBR, EXPORTBR, IMPORTBR, IPCA e ICMSBR. ${ }^{12}$

Como a finalidade desta pesquisa é verificar o impacto da política monetária sobre as economias capixaba e brasileira, as funções de impulso-resposta tentaram captar os efeitos das variáveis M4, TXJUROS e TXCAMBIO sobre as demais séries consideradas, tanto para o Espírito Santo quanto para o Brasil. Nos Gráficos 1 e

$10 \quad$ Destaca-se que é comum, entre os estudos que trabalham com o modelo VAR, a realização do exercício de decomposição da variância (DV) como complemento à análise das funções de impulso-resposta. No entanto, em função da elevada quantidade de variáveis utilizadas neste trabalho, o que estenderia demasiadamente o seu tamanho, optou-se por dar ênfase à comparação entre as funções de impulso-resposta do Espírito Santo e do Brasil, deixando para futuros estudos uma análise complementar de decomposição da variância.

11 Vale lembrar que vários autores brasileiros passaram a justificar a ordenação das variáveis em seus modelos com base no teste de causalidade de Granger (Block exogeneity wald tests). No entanto, segundo Cavalcanti (2010), a identificação do ordenamento do modelo VAR através da causalidade Granger não seria apropriada, pois a ordenação de Cholesky indica uma causalidade contemporânea entre as variáveis, ao passo que o teste de Granger refere-se a uma causalidade de precedência temporal. Assim, com o intuito de evitar a "persistência no erro" (CAVALCANTI, 2010), será adotado o método de informação a priori neste trabalho, muito embora seja necessário dizer não é o único método alternativo ao de causa Granger.

12 Devido ao grande número de variáveis utilizadas e à importância da ordenação de Cholesky para a correta estimação das funções de impulso-resposta, tentaram-se outros ordenamentos (o que pode ser considerado um teste de Robustez), que não alteraram significantemente tais funções. 
2, são demonstradas as FIRs, na ocorrência de um choque na variável M4, sobre as economias do Espírito Santo e do Brasil, respectivamente. As linhas contínuas equivalem às funções impulso-resposta e as linhas tracejadas equivalem a intervalos de confiança correspondentes a dois erros-padrão.

Gráfico 1 - Funções de impulso-resposta para o Espírito Santo (impulso em M4)

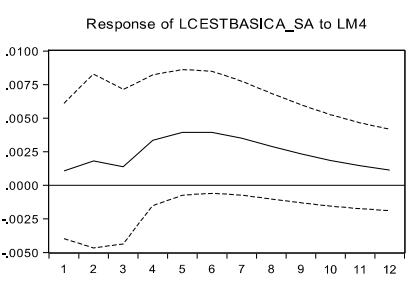
Response to Cholesky One S.D. Innov ations \pm 2 S.E.
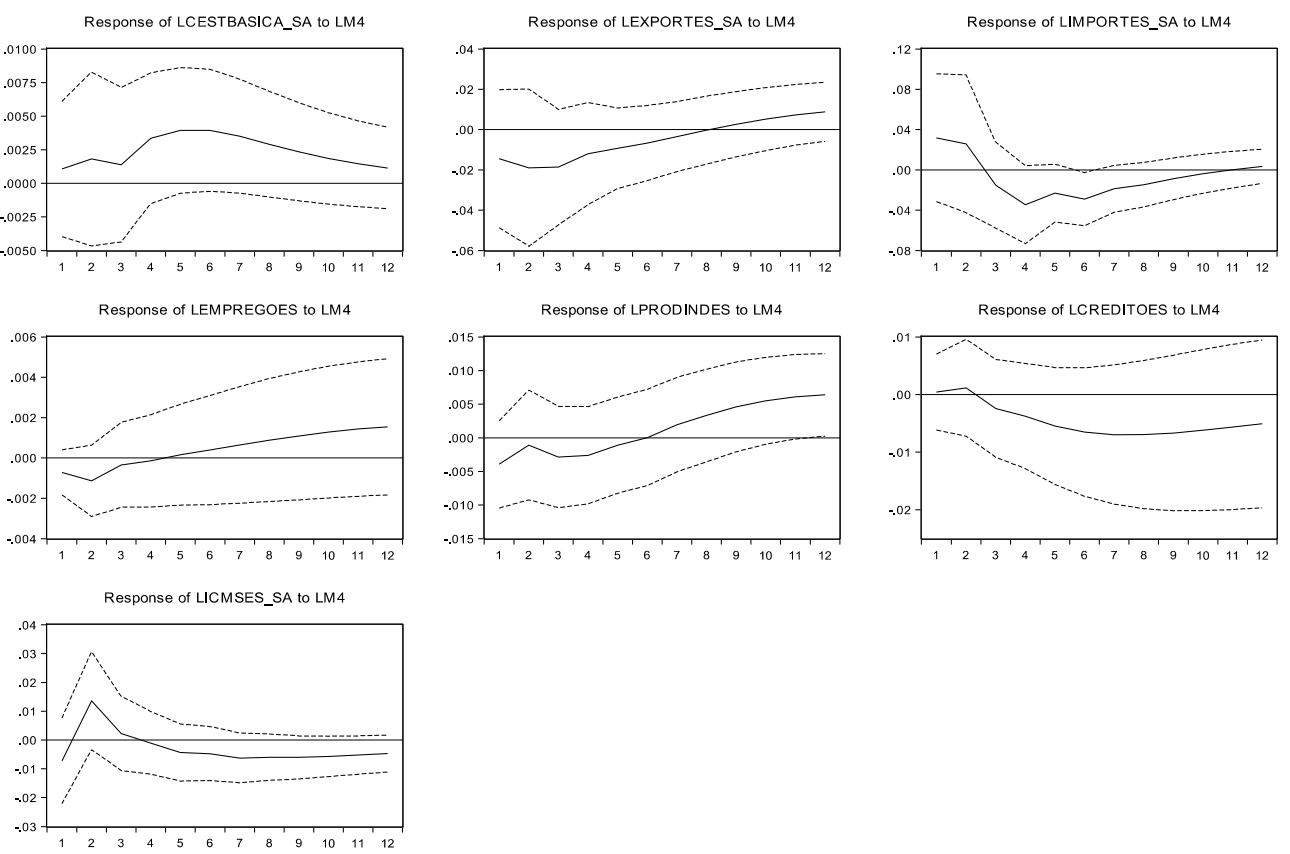

Fonte: Elaboração própria.

Notas: 1) L: indica que as variáveis estão expressas em logaritmos; 2) SA: série dessazonalizada.

Inicialmente, toma-se o caso do efeito de M4 sobre a produção industrial capixaba e a do Brasil. Em relação à PRODINDES, nota-se que uma elevação de um desvio-padrão em $\mathrm{M} 4$ acarreta um impacto negativo na produção até o quinto período. Após o sexto mês, o efeito torna-se positivo, com aumento durante o restante do período, sendo que após os 12 meses a produção fica acima do nível inicial (antes do choque em M4). Quanto à PRODINDBR, após um choque inicial em M4, reduz-se até o sétimo mês. Logo após, a partir do oitavo período, a produção industrial sofre impactos positivos, ficando acima do nível inicial. De acordo com o referencial novo-keynesiano, a política monetária tem impactos reais sobre a economia, ao menos no curto prazo, devido à rigidez relativa de preços e salários nesse horizonte de tempo. Logo, os resultados das simulações eram esperados, visto que são respostas temporais da economia num horizonte de até 12 meses (curto prazo). 
No caso do valor da cesta básica em Vitória (CESTBASICA), nota-se crescimento do mesmo durante os 12 meses após o choque em M4, conforme esperado. Já no que tange ao IPCA, divergindo do esperado, tal variável sofre impactos negativos em todos os meses a partir do choque. Também merece destaque os efeitos de M4 sobre o crédito. Verifica-se que o CREDITOES é positivamente afetado pela variação em M4 até o segundo mês, sendo que depois o efeito é negativo. No que tange ao CREDITOBR, os efeitos positivos do choque em M4 acontecem durante todos os 12 meses.

Gráfico 2 - Funções de impulso-resposta para o Brasil (impulso em M4)

Response of LIPCA to LM4

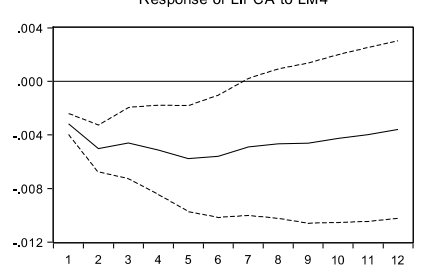

Response of LEMPREGOBR to LM4

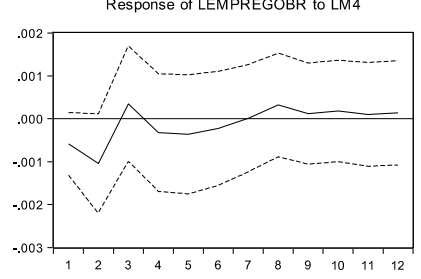

Response of LICMSBR_SA to LM4

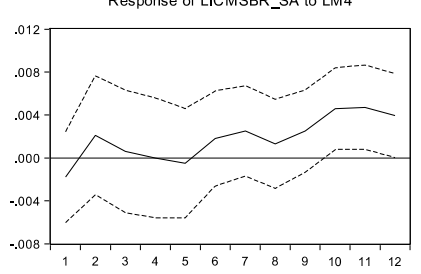

Response to Cholesky One S.D. Innov ations \pm 2 S.E. Response of LEXPORTBR_SA to LM4

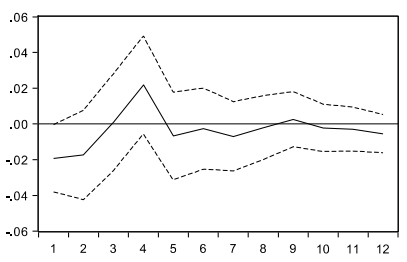

Response of LPRODINDBR to LM4

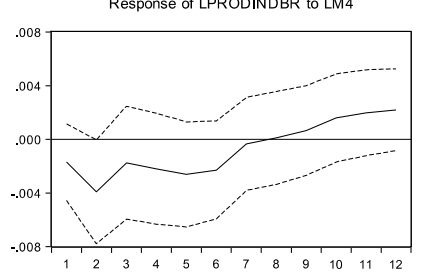

Response of LIMPORTBR_SA to LM4

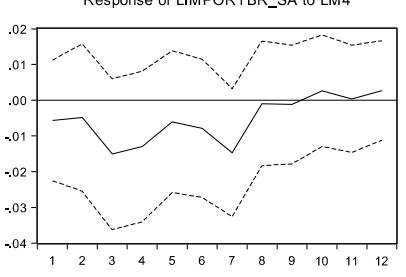

Response of LCREDITOBR to LM4

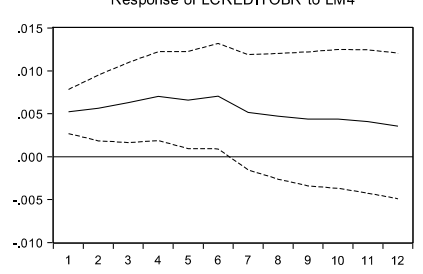

Fonte: Elaboração própria.

Notas: 1) L: indica que as variáveis estão expressas em logaritmos; 2) SA: série dessazonalizada.

Observa-se que a variável EXPORTES somente aumenta, após os choques em M4, a partir do oitavo mês. Quanto à EXPORTBR, o efeito positivo se faz com mais significância no quarto período após o choque. Para a variável IMPORTES, tem-se um aumento no primeiro e no segundo mês após o choque. Do terceiro mês em diante, o efeito torna-se negativo, e a tendência é de estabilidade após os 12 meses (os efeitos de M4 sobre a IMPORTES são dissipados com o tempo). As importações do Brasil (IMPORTBR) somente são impactadas positivamente depois do décimo mês. 
A variável ICMSES apresenta efeito negativo no primeiro mês, revertendo-se para efeitos positivos no segundo e no terceiro mês. Após o quarto período, o ICMSES reduz-se novamente até o fim dos 12 meses. Em relação ao ICMSBR, tirando o primeiro e o quinto período, os efeitos de M4 sobre tal variável são positivos. A variável referente ao nível de emprego, seja estadual ou nacional, diminui inicialmente, logo após o impacto em M4. No entanto, ao longo dos 12 meses há uma recuperação, ficando o nível de emprego acima do patamar inicial, antes do choque em M4.

Os Gráficos 3 e 4 apresentam os resultados das estimações das funções de impulso-resposta, a partir de um choque na variável TXJUROS, sobre as economias do Espírito Santo e do Brasil, respectivamente. Nota-se que, para a economia capixaba o aumento de um desvio-padrão na TXJUROS leva a uma redução da produção industrial (exceto no primeiro mês). Os choques permanecem negativos até o $12^{\circ}$ período. Quanto à PRODINBR, esta começa a reduzir-se a partir do quinto mês, com tendência de estabilidade após 12 períodos. Esses resultados eram esperados, uma vez que a elevação da taxa de juros tende a reduzir o nível de investimento. Cabe mencionar que os efeitos da taxa de juros parecem impactar mais a produção industrial capixaba do que a brasileira.

Gráfico 3 - Funções de impulso-resposta para o Espírito Santo (impulso em TXJUROS)
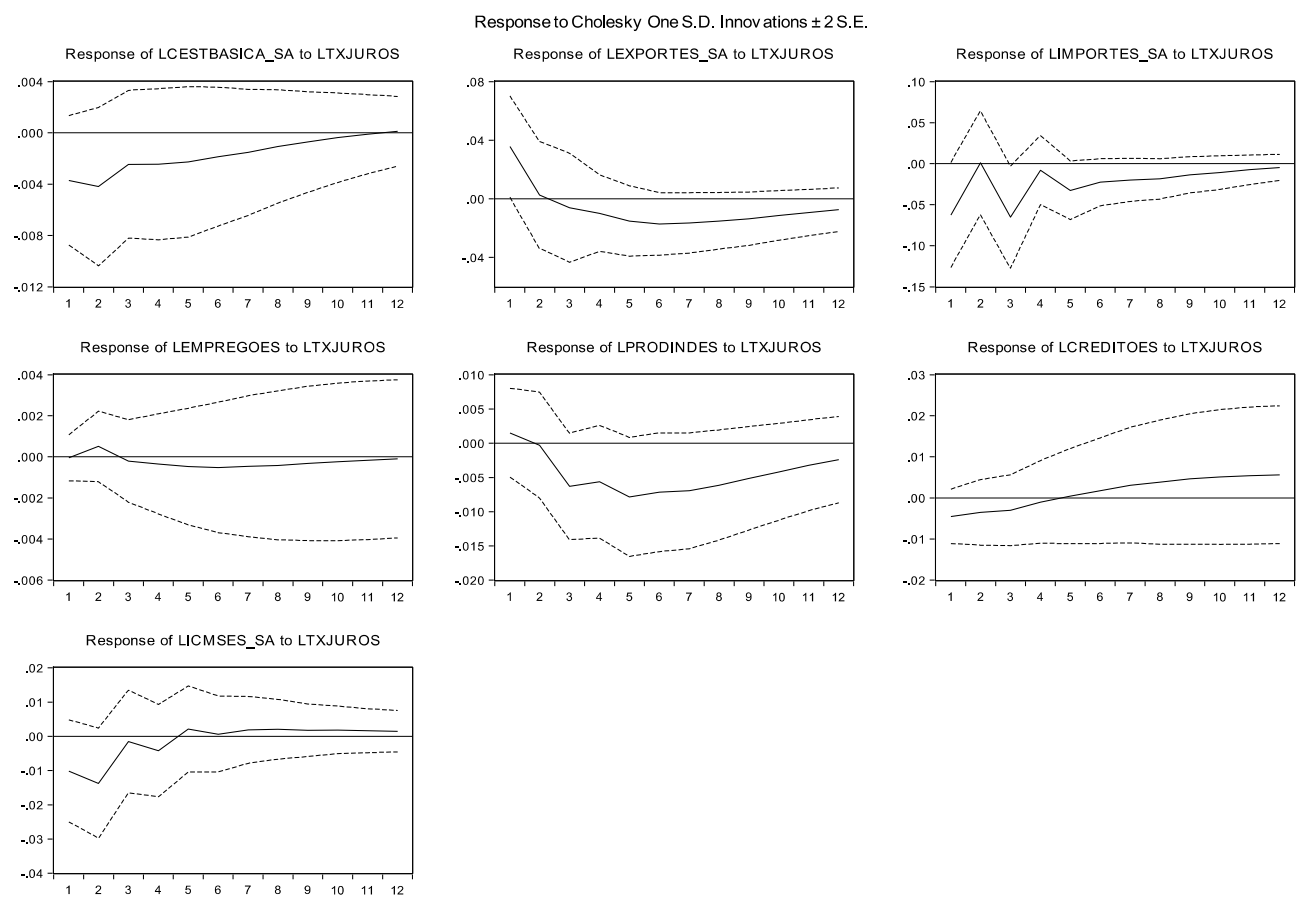

Fonte: Elaboração própria.

Notas: 1) L: indica que as variáveis estão expressas em logaritmos; 2) SA: série dessazonalizada. 
No caso do valor da cesta básica, percebe-se uma redução do mesmo durante todo o período, tendendo assintoticamente a zero após os 12 períodos. O IPCA também decresce durante o período de 12 meses, após o choque na taxa de juros, não caminhando para estabilidade. Em relação às variáveis EXPORTES e EXPORTBR, é possível constatar que, após o choque inicial na taxa de juros, ocorre um aumento no primeiro mês. A partir do segundo mês, a EXPORTES sofre impactos negativos até o $12^{\circ}$ período. Já a variável EXPORTBR decresce no segundo mês, recuperando-se no quarto mês, e tendendo à estabilidade depois de 12 meses. As importações do Espírito Santo decrescem nos 12 meses e tendem assintoticamente a zero. Já as importações do Brasil, após algumas oscilações, caminham para estabilidade.

Referente aos impactos da taxa de juros sobre o crédito, os resultados foram os seguintes: no Espírito Santo, o choque na taxa de juros reduz o crédito até o quarto mês. Depois, há certa recuperação e estabilidade um pouco acima do nível inicial. O CRETIDOBR apresenta padrão semelhante ao caso do Espírito Santo. Nota-se que a variável EMPREGOES cresce no segundo mês. Depois, passa por sucessivas reduções até a estabilidade no décimo segundo mês. A partir de uma redução no primeiro mês, o nível de emprego no Brasil cresce até o oitavo mês, para então voltar a diminuir. Quanto à variável ICMS, no Espírito Santo a arrecadação decresce até o quarto período. No Brasil, a arrecadação aumenta no primeiro e no segundo mês, diminui no terceiro, e depois de algumas oscilações fica superior ao nível inicial.

Gráfico 4 - Funções de impulso-resposta para o Brasil (impulso em TXJUROS)

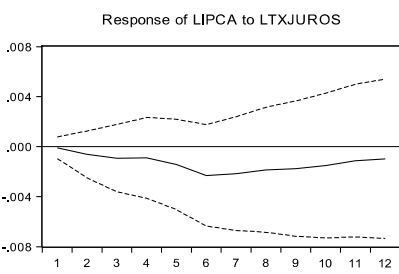

Response to Cholesky One S.D. Innov ations \pm 2 S.E.

Response of LEXPORTBR_SA to LTXJUROS

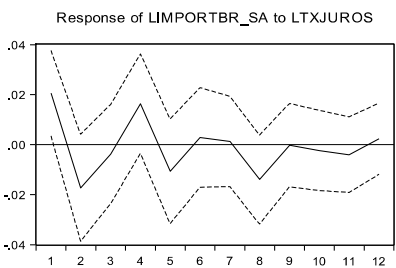

Response of LEMPREGOBR to LTXJUROS
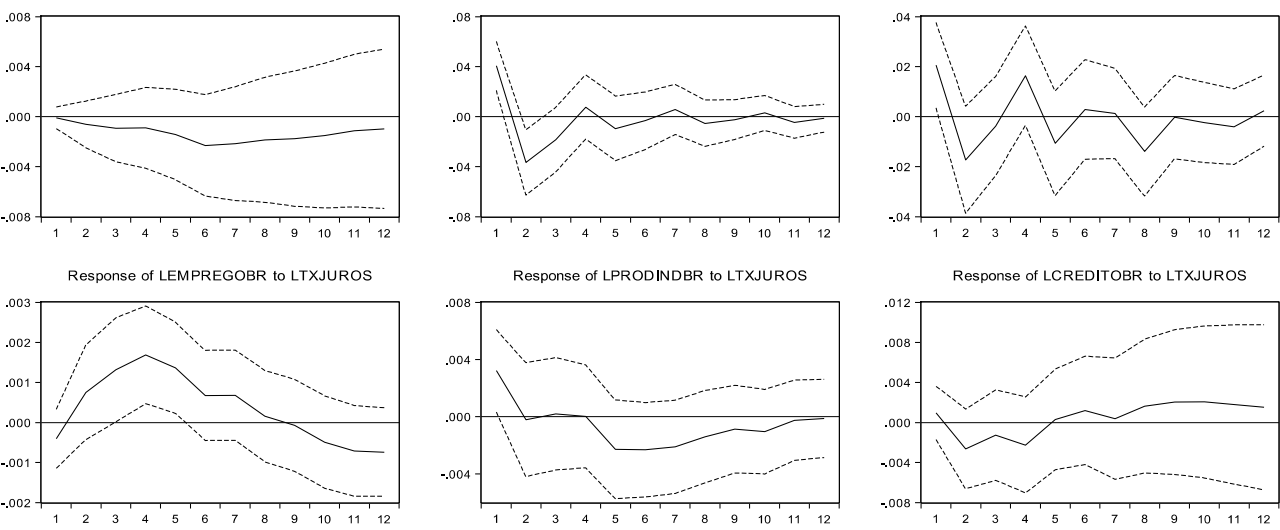

Response of LICMSBR_SA to LTXJUROS

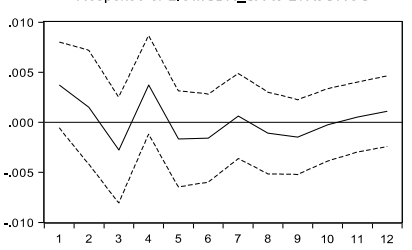

Fonte: Elaboração própria

Notas: 1) L: indica que as variáveis estão expressas em logaritmos; 2) SA: série dessazonalizada. 
Por fim, os Gráficos 5 e 6 demonstram as funções de impulso-resposta, na presença de um choque na variável TXCAMBIO, sobre as economias do Espírito Santo e do Brasil, respectivamente. Em um primeiro momento, vale observar os reflexos da TXCAMBIO sobre as exportações e importações capixabas e brasileiras. No caso da EXPORTES, nota-se uma elevação no decorrer de quase todo o período após o choque, exceto no quarto mês. Em relação à EXPORTBR, verifica-se crescimento constante até o quinto mês, com posterior oscilação para mais ou para menos. Conforme esperado, a taxa de câmbio tem forte impacto sobre as exportações. Quanto às importações, no Espírito Santo somente apresentam impacto positivo no segundo mês. Nos outros períodos, os efeitos são negativos e a tendência é de estabilidade após os 12 meses. Referente ao Brasil, as importações seguem o padrão do Espírito Santo, com a diferença de que o impacto também é positivo no terceiro mês.

Destaca-se que, segundo Taylor (1995), o mecanismo de transmissão monetária é definido como o processo através do qual as decisões de política monetária são transmitidas para o produto real e a inflação. Dessa maneira, as decisões de política monetária podem ser modeladas como mudanças na taxa de juros de curto prazo, o que afeta o produto real através de variáveis como oferta de crédito, renda e taxa de câmbio.

No caso específico do mecanismo de câmbio, ocorre, segundo Mishkin (1996), ao afetar a competitividade e as exportações líquidas, via variação da taxa de câmbio real, no curto prazo. Assim, o grau de abertura econômica desigual entre países e regiões é o que originaria diferentes variações na atividade econômica. Nesse sentido, Magalhães e Toscano (2009) estimaram, para o período 2004/2009, que o grau de abertura do Espírito Santo foi de $48 \%$, mais de duas vezes maior do que o do Brasil. Dessa forma, conforme esperado, tanto as exportações quando as importações do estado foram mais afetadas pelo choque na taxa de câmbio do que no caso do Brasil.

O valor da cesta básica do município de Vitória, após um choque na TXCAMBIO, reduz-se até o terceiro mês. Ocorre uma recuperação entre o quinto e o oitavo mês, para depois ficar abaixo do nível inicial. Para o IPCA, o efeito de TXCAMBIO é positivo nos 12 meses. Essa elevação após o impacto na taxa de câmbio era esperada, uma vez que uma taxa de câmbio mais alta encarece as importações e tendem a inflacionar os preços. 
Gráfico 5 - Funções de impulso-resposta para o Espírito Santo (impulso em TXCAMBIO)

Response of LCESTBASICA_SA to LTXCAMBIO_SA Response to Cholesky One S.D. Innov ations \pm 2 S.E.

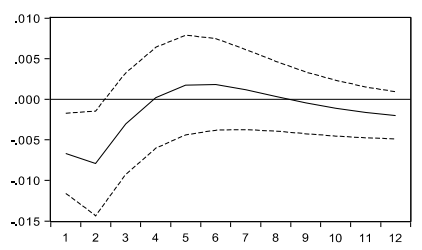

Response of LEXPORTES_SA to LTXCAMBIO_SA
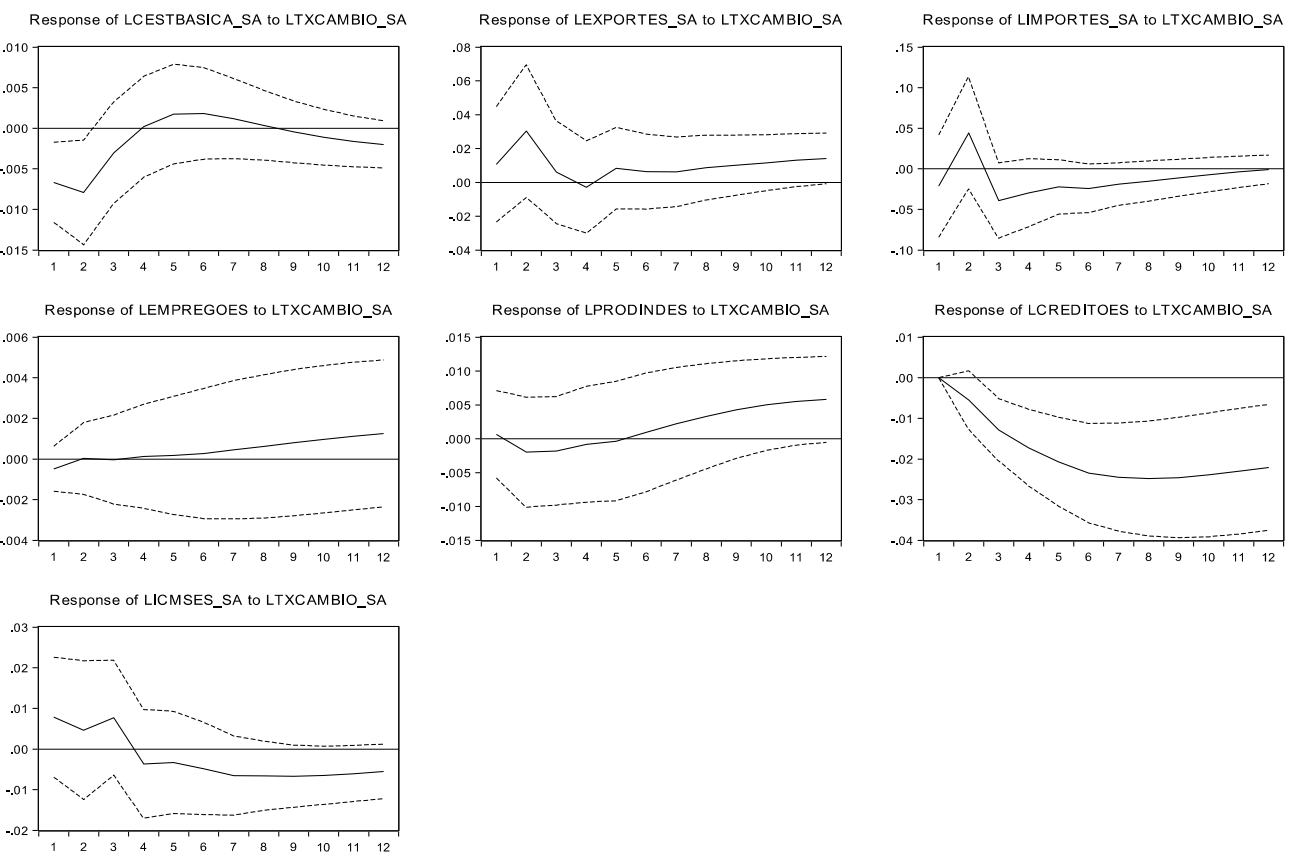

Fonte: Elaboração própria.

Notas: 1) L: indica que as variáveis estão expressas em logaritmos; 2) SA: série dessazonalizada. 
Gráfico 6 - Funções de impulso-resposta para o Brasil (impulso em TXCAMBIO)

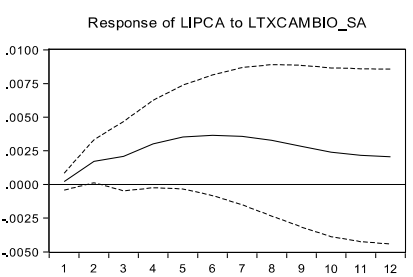

Response to Cholesky One S.D. Innov ations \pm 2 S.E.

Response of LEXPORTBR_SA to LTXCAMBIO_SA

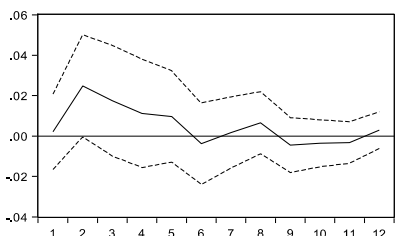

Response of LIMPORTBR_SA to LTXCAMBIO_SA
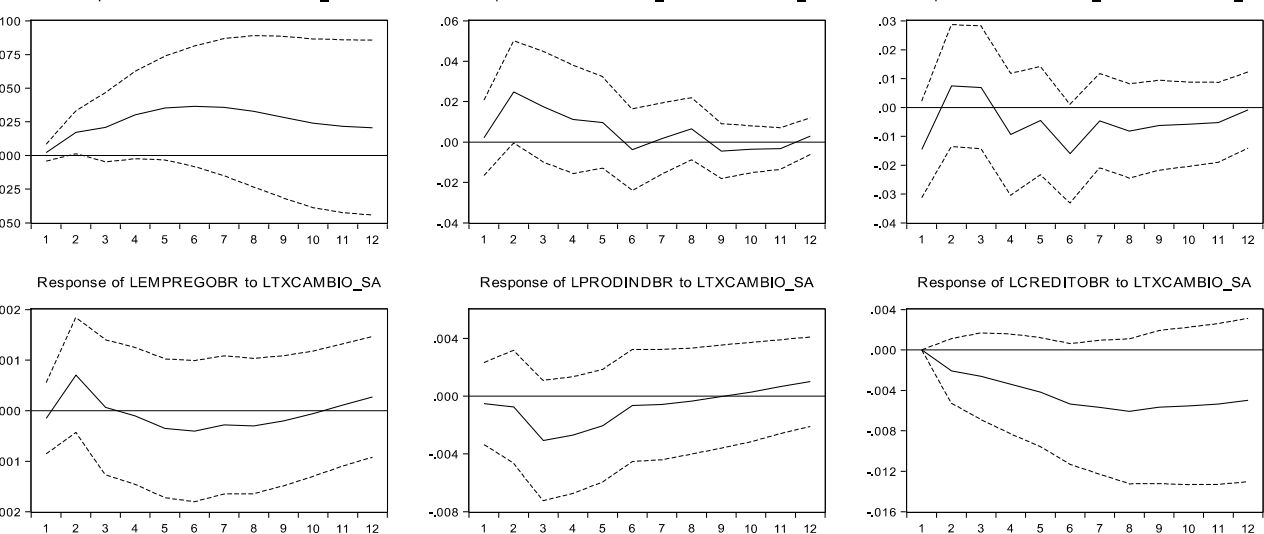

Response of LICMSBR_SA to LTXCAMBIO_SA
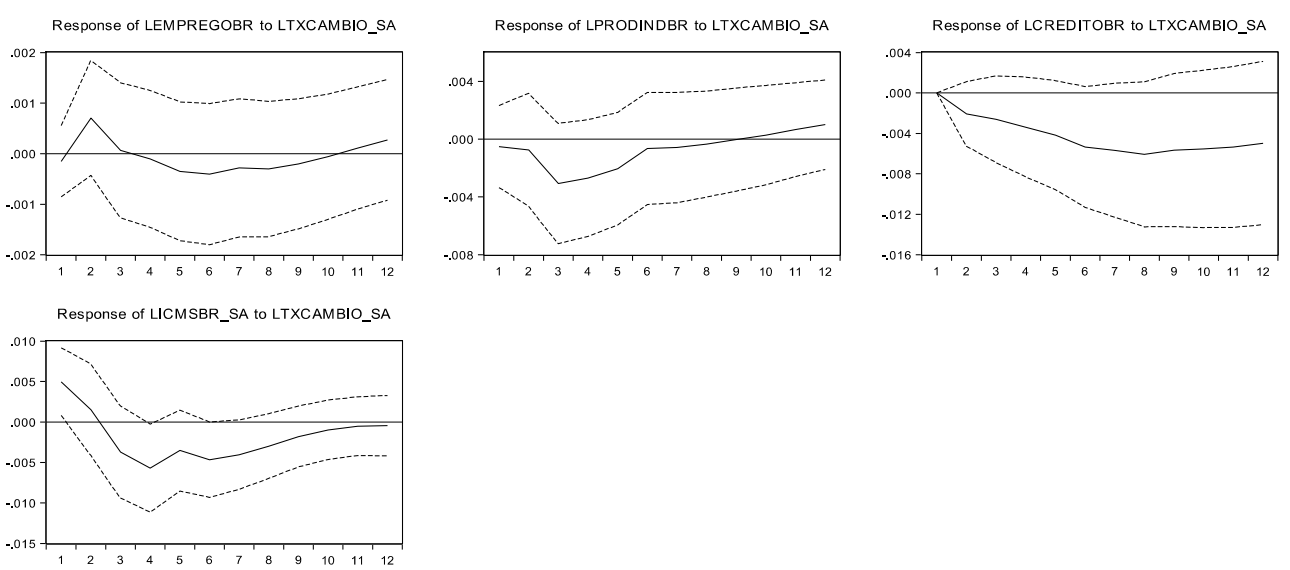

Fonte: Elaboração própria.

Notas: 1) L: indica que as variáveis estão expressas em logaritmos; 2) SA: série dessazonalizada.

Em relação à variável PRODINDES, verifica-se que após uma fase de impacto negativo, sendo pequeno, ocorre, um forte crescimento do nível de atividade industrial depois do sexto mês. Para a economia brasileira, os efeitos positivos da taxa de câmbio demoram um período mais longo para acontecerem. Tanto para a economia do Espírito Santo quanto para a economia brasileira, a produção industrial fica acima do nível inicial anterior ao choque na taxa de câmbio.

Observa-se uma forte queda no nível de crédito, no Espírito Santo e no Brasil, a partir de um choque na taxa de câmbio. O nível de emprego parece ser afetado mais positivamente na economia capixaba, pois a economia brasileira demonstra alguns meses de choque negativo. A arrecadação de ICMS, por sua vez, aumenta até o terceiro período para o Espírito Santo. Após o quarto mês, os choques são negativos. Para o Brasil, a arrecadação eleva-se até o segundo mês, passando por choques negativos do terceiro ao décimo segundo mês.

\section{Considerações Finais}

O objetivo do presente trabalho foi analisar empiricamente o impacto da política monetária na economia capixaba e brasileira (esta última como base de comparação). Utilizando a técnica de vetores autorregressivos e uma base de dados 
para o período 2000-2010, descobriu-se que, grosso modo, o Espírito Santo é mais afetado pela política monetária do que o Brasil como um todo, o que caracteriza a grande contribuição empírica deste artigo.

A partir dos resultados obtidos, as principais conclusões foram os seguintes:

a) quanto ao nível de atividade (produção industrial e emprego), notou-se que, para o Espírito Santo, choques na taxa de juros o afetaram muito mais do que a taxa de câmbio e M4, nessa ordem. Já para o Brasil, a situação é diferente, pois inovações em M4 e na taxa de câmbio impactaram mais o nível de atividade do que a taxa de juros. Em todas as simulações, os impactos foram mais negativos no estado do que no país;

b) no que tange às variáveis de comércio exterior, impulsos na taxa de juros provocaram mais oscilações negativas do que taxa de câmbio e M4 no Espírito Santo. Contudo, para o país, choques nas três variáveis (juros, câmbio e M4) parecem afetar de maneira bem similar às suas exportações e importações;

c) a estabilidade de preços, objetivo primário da política monetária, é alcançada mais firmemente com variações na taxa de juros e em M4, nessa ordem. Impactos positivos na taxa de câmbio tendem a expandir o nível de preços, pelo menos no curto prazo. Esses resultados são similares para o Espírito Santo e o Brasil;

d) no que diz respeito ao crédito, inovações na taxa de câmbio afetaram mais negativamente o crédito, tanto no Espírito Santo quanto no Brasil, do que impulsos na taxa de juros e em M4;

e) por fim, sobre o ICMS, a taxa de juros afetou mais a sua arrecadação no estado, diferente do caso nacional, em que a taxa de câmbio teve o maior efeito entre as variáveis testadas.

Dessa forma, embora o Espírito Santo tenha uma participação modesta na economia nacional (pouco mais $2 \%$ do PIB), contribui substancialmente para o comércio exterior brasileiro (cerca de $5 \%$ ), o que, ao mesmo tempo, representa aproximadamente $50 \%$ do PIB local. Assim, seria prudente para as autoridades econômicas, e principalmente para o $\mathrm{BCB}$, buscar uma melhor avaliação dos mecanismos de transmissão e também desses impactos na economia capixaba. Esse melhor entendimento poderia resultar em políticas coordenadas que tivessem um efeito compensatório para a economia local, mais vulnerável às medidas de política monetária.

Por fim, embora um governo estadual disponha de pouca margem de manobra para fazer frente a políticas monetárias restritivas, e partindo da premissa de que os seus objetivos básicos são o crescimento econômico e a sustentabilidade 
financeira das finanças públicas estaduais, algumas recomendações gerais podem ser feitas para o Espírito Santo:

a) aumentar os investimentos com recursos do Tesouro estadual, sobretudo quando o $\mathrm{BCB}$ estiver usando mais instrumentos que afetem a taxa de juros e taxa de câmbio do que M4, para tentar contrabalançar a possível queda na atividade econômica decorrente da política monetária contracionista. Vale notar que na análise anteriormente, a arrecadação de ICMS variou menos (e em muitos momentos foi uma variação positiva) em resposta a choques em M4 do que na taxa de juros e na taxa de câmbio;

b) disponibilizar crédito em condições atrativas para as empresas locais, sobretudo as de pequeno e médio porte, por meio de seus agentes de crédito, o Banco do Estado do Espírito Santo (Banestes) e o Banco de Desenvolvimento do Espírito Santo (Bandes), uma vez que, em tempos de políticas monetárias restritivas, o crédito tende a ficar escasso e mais caro no sistema financeiro privado.

\section{Referências}

ARAÚJO, E. Medindo o impacto regional da política monetária brasileira: uma comparação entre as regiões Nordeste e Sul. Revista Econômica do Nordeste, v. 35, n. 3, p. 356-393, 2004.

ARNOLD, I.; VRUGT, E. Regional effects of monetary policy in the Netherlands. International Journal of Business and Economics, v. 1, n. 2, p. 123-134 2002.

BALL, L. Efficient rules for monetary policy. International Finance, v. 2, n. 1, p. 63-83, Apr. 1999.

BANCO CENTRAL DO BRASIL. Estatísticas de crédito e atividade bancária dos estados. 2011. Disponível em: <http://www.bcb.gov.br>. Acesso em: 30 jan. 2011.

BERNANKE, B.; GERTLER, M. Inside the black box: the credit channel of monetary policy transmission. Journal of Economics Perspectives, v. 9, n. 4, p. 27-48, 1995.

BERTANHA, M.; HADDAD, E. Efeitos regionais da política monetária no Brasil: impactos e transbordamentos espaciais. Revista Brasileira de Economia, v. 62, n. 1, p. 3-29, 2008.

BLANCHARD, O.; GALÍ, J. Labor markets and monetary policy: a new Keynesian model with unemployment. Cambridge, MA: NBER, 2008. (NBER Working Paper Series, n. 13.897).

BOGDANSKI, J.; TOMBINI, A. A.; WERLANG, S. C. Implementing inflation targeting in Brazil. Brasília, DF: Central Bank of Brazil, July 2000. (BCB Working paper series, n. 1).

BUENO, R. D. L. S. Econometria de séries temporais. São Paulo: Cengage Learning, 2008. $300 \mathrm{p}$.

CAÇADOR, S. B.; GRASSI, R. A. Olhar crítico sobre o desempenho recente da economia capixaba: uma análise a partir da literatura de desenvolvimento regional e de indicadores de inovação. Revista Econômica do Nordeste, v. 40, n. 3, p. 453-480, 2009. 
CAMPBELL, J. Y.; PERRON, P. Pitfalls and opportunities: what macroeconomists should know about unit roots. In: BLANCHARD, O. J.; FISCHER, S. (Ed.). NBER Macroeconomics annual. Cambridge: The MIT Press, 1991. p. 141-201.

CAMURI, P. A. Dívida pública, política fiscal e vulnerabilidade externa no Brasil. 2005. 88 f. Dissertação (Mestrado Economia) - Programa de Pós-graduação em Economia, Centro de Desenvolvimento e Planejamento Regional, Universidade Federal de Minas Gerais, Belo Horizonte, 2005.

CARLINO, G.; DEFINA, R. The differential regional effects of monetary policy: evidence from the U.S. States. Philadelphia, PA: Federal Reserve Bank of Philadelphia, 1997. (Working Paper n. 97, 12).

CAVALCANTI, M. A. F. H. Identificação de modelos VAR e causalidade de Granger: uma nota de advertência. Economia Aplicada, v. 14, n. 2, p. 251-260, 2010.

CECCHETTI, S. G. Legal structure, financial structure, and the monetary policy transmission mechanism. Economic Policy Review, v. 5, n. 2, p. 9-28, 1999.

CÉSPEDES, B.; LIMA, E.; MAKA, A. Monetary policy, infation and the level of economic activity in Brazil after the real plan: stylized facts from SVAR models. Revista Brasileira de Economia, v. 62, n. 2, p. 123-160, 2008.

CHUMVICHITRA, P. Efeitos regionais diferenciados da política monetária: a experiência brasileira. Revista Contemporânea de Economia e Gestão, v. 2, n. 1, p. 7-22, 2004.

CLARIDA, R.; GALI, J.; GERTLER, M. The science of monetary policy: a new Keynesian perspective. Journal of Economic Literature, v. 37, n. 4, p. 1661-1707, 1999.

DEDOLA, L.; LIPPI, F. The monetary transmission mechanism: evidence from the industries of five OECD countries. European Economic Review, v. 49, n. 6, p. 1543-1569, 2005.

DI GIACINTO, V. "Differential regional effects of monetary policy: a geographical SVAR approach”. International Regional Science Review, v. 26, n. 3, p. 313-341, 2003.

DICKEY, D. A.; FULLER, W. A. Likelihood ratio statistics for autoregressive time series with a unit root. Econometrica, v. 49, n. 4, p. 1057-1073, 1981.

ENGLE, R. F.; GRANGER, C. W. J. Cointegration and error correction: representation, estimation, and testing. Econometrica, v. 55, n. 2, p. 251-276, 1987.

FONSECA, M. W.; MEDEIROS, M. L. Impactos regionais da política monetária no Brasil pósregime de metas de inflação. Ensaios FEE, Porto Alegre, v. 32, n. 2, p. 515-552, 2011.

FONSECA, M.; VASCONCELOS, M. Política monetária: mecanismos de transmissão e impactos diferenciados nas regiões e estados do Brasil. Revista Econômica do Nordeste, v. 34, n. 4, p. 532-561, 2003.

FORNI, M. et al. The generalized dynamic-factor model: identification and estimation. The Review of Economics and Statistics, v. 82, n. 4, p. 540-554, 2000.

. The generalized dynamic-factor model: consistency and rates. Journal of Econometrics, v. 114, n. 2, p. 231-255, 2004.

FRANCIS, N.; OWYANG, M. T.; SEKHPOSYAN, T. The local effects of monetary policy. St. Louis, MO: Federal Reserve Bank of St. Louis, 2011. (Working Paper Series, n. 048C).

GALÍ, J.; GERTLER, M. Macroeconomic modeling for monetary: policy evaluation. Journal of Economic Perspectives, v. 21, n. 4, p. 25-45, 2007. 
GARRISON, C. B.; CHANG, H. S. The effects of monetary forces in regional economic activity. Journal of Regional Science, v. 19, n. 1, p. 15-29, 1979.

GOODFRIEND, M.; KING, R. G. The new neoclassical synthesis and the role of monetary policy. In: BERNANKE, B.; ROTEMBERG, J. (Ed.). NBER Macroeconomics Annual. Cambridge, MA: MIT Press, 1997. v. 12. p. 231-296.

GRÔPPO, G. Causalidade das variáveis macroeconômicas sobre o IBOVESPA. 2004. 107 f. Dissertação (Mestrado em Economia Aplicada) - Programa de Pós-graduação em Economia Aplicada, Escola Superior de Agricultura Luiz de Queiroz Piracicaba, Universidade de São Paulo, Piracicaba, SP, 2004.

IBGE. Estatísticas de cadastro empresarial de estados e do Brasil. 2011. Disponível em: <http://www.ibge.gov.br>. Acesso em: 30 jan. 2011.

Estatísticas de PIB de estados e do Brasil. 2011. Disponível em: < http://www.ibge.

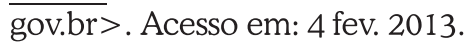

KWIATKOWSKI, D. et al. Testing the null hypothesis of stationarity against the alternative of unit root. Journal of Econometrics, v. 54, n. 1, p. 159-178, 1992.

MAGALHÃES, M. Preços de commodities e nível de atividade no Espírito Santo: um estudo econométrico. Vitória, ES: Instituto Jones dos Santos Neves, 2010. (Texto para discussão, n. 13).

MAGALHÃES, M.; CASTRO, M.; TOSCANO, V. Impactos macroeconômicos da incerteza e da taxa de juros: uma comparação empírica ente Brasil e Espírito Santo. Vitória, ES: Instituto Jones dos Santos Neves, 2009. (Texto para discussão, n. 6).

MAGALHÃES, M.; RIBEIRO, A. P. Fatos estilizados nos ciclos de negócios no Estado do Espírito Santo: uma abordagem quantitativa. In: ENCONTRO DE ECONOMIA BAIANA, 6., 2010, Salvador. Anais... Salvador: Programa de Pós-Graduação em Economia da Universidade Federal da Bahia, 2010.

MAGALHÃES, M.; TOSCANO, V. Estimativas de grau de abertura para a economia do Espírito Santo. Vitória, ES: Instituto Jones dos Santos Neves, 2009. (Nota Técnica n. 8).

MISHKIN, F. S. The channels of monetary transmission: lessons for monetary policy. Banque de France Bulletin Digest, n. 27, p. 33-44, Mar. 1996.

MOREIRA, R. R. O tripé inflation targeting, superávits primários e flutuação cambial: análise de regimes alternativos sob choques de oferta e cambiais. In: ENCONTRO INTERNACIONAL DA ASSOCIAÇÃO KEYNESIANA BRASILEIRA, 4., 2011, Rio de Janeiro. Anais... Rio de Janeiro: AKB, 2011.

MOTA, F. C. M. Integração e dinâmica regional: o caso capixaba (1960-2000). 2002. $161 \mathrm{f}$. Tese (Doutorado em Economia) - Instituto de Economia, Universidade Estadual de Campinas, Campinas, SP, 2002.

OREIRO, J. L. et al. Determinantes macroeconômicos do spread bancário no Brasil: teoria e evidência recente. Economia Aplicada, v. 10, n. 4, p. 609-634, 2006.

PHILLIPS, P. C. B.; PERRON, P. Testing for unit roots in time series regression. Biometrika, v. 75, n. 3, p. 335-346, 1988.

ROCHA, B. P. Ensaios sobre economia bancária e política monetária no Brasil em uma abordagem regionalizada. Tese (Doutorado em Economia) - Departamento de Economia, Faculdade de Economia, Administração e Contabilidade, Universidade de São Paulo, São Paulo, 2007. 
ROCHA, R. M.; SILVA, M. E. A.; GOMES, S. M. F. P. O. Por que os estados brasileiros têm reações assimétricas a choques na política monetária? Revista Brasileira de Economia, v. 65, n. 4, p. 413-441, 2011.

SALA, L. Monetary transmission in the Euro area: a factor model approach. Economics Working Paper Archive, 2002. (Working Paper n. 020505).

SIMS, C. Macroeconomics and reality. Econometrica, v. 48, n. 1, p. 1-48, 1980.

SIMS, C.; STOCK, J.; WATSON, M. Inference in linear time series models with some unit roots. Econometrica, v. 58, n. 1, p. 113-144, 1990.

SVENSSON, L. E. O. Inflation forecast targeting: implementing and monitoring inflation targets. European Economic Review, v. 41, n. 6, p. 1111-1146, 1997.

TAYLOR, J. Discretion versus policy rules in practice. Carnegie-Rochester Conference Series on Public Policy. v. 39, n. 1, p. 195-214, 1993.

. The monetary transmission mechanism: an empirical framework. Journal of Economic Perspectives, v. 9, n. 4, p. 11-26, Autumn 1995.

TOMAZZIA, E. C.; MEURER, R. O mecanismo de transmissão da política monetária no Brasil: uma análise em VAR por setor industrial. Revista de Economia Aplicada, v. 13, n. 4, p. 371-398, 2009.

Recebido em: 27/03/2012. Aceito em: 27/03/2013. 